\title{
Climatology and modeling of ionospheric scintillations and irregularity zonal drifts at the equatorial anomaly crest region
}

\author{
Marcio T. A. H. Muella ${ }^{1}$, Marcelo H. Duarte-Silva ${ }^{1}$, Alison O. Moraes ${ }^{2}$, Eurico R. de Paula ${ }^{3}$, Luiz F. C. de Rezende ${ }^{3}$, \\ Lucilla Alfonsi $^{4}$, and Bruno J. Affonso ${ }^{5}$ \\ ${ }^{1}$ Universidade do Vale do Paraíba-UNIVAP, Institute of Research and Development-IP\&D, São José dos Campos, \\ São Paulo, 12.244-000, Brazil \\ ${ }^{2}$ Instituto de Aeronáutica e Espaço-IAE, São José dos Campos, São Paulo, 12.228-904, Brazil \\ ${ }^{3}$ Instituto Nacional de Pesquisas Espaciais-INPE, São José dos Campos, São Paulo, 12.227-010, Brazil \\ ${ }^{4}$ Istituto Nazionale di Geofisica e Vulcanologia-INGV, Rome, 00143, Italy \\ ${ }^{5}$ Empresa Brasileira de Aeronáutica S.A.-Embraer, São José dos Campos, São Paulo, 12.227-901, Brazil
}

Correspondence to: Marcio T. A. H. Muella (mmuella@univap.br)

Received: 29 April 2017 - Revised: 20 September 2017 - Accepted: 3 October 2017 - Published: 8 November 2017

\begin{abstract}
In this study the climatology of ionospheric scintillations and the zonal drift velocities of scintillationproducing irregularities are depicted for a station located under the southern crest of the equatorial ionization anomaly. Then, the $\alpha-\mu$ ionospheric fading model is used for the firstand second-order statistical characterization of amplitude scintillations. In the statistical analyzes, data are used from single-frequency GPS receivers acquired during $\sim 17$ years (September 1997-November 2014) at Cachoeira Paulista $\left(22.4^{\circ} \mathrm{S} ; 45.0^{\circ} \mathrm{W}\right)$, Brazil. The results reveal that the nocturnal occurrence of scintillations follows the seasonal distribution of plasma bubble irregularities observed in the longitudinal sector of eastern South America. In addition to the solar cycle dependence, the results suggest that the occurrence climatology of scintillations is also modulated by the secular variation in the dip latitude of Cachoeira Paulista, since the maximum occurrence of scintillations during the peak of solar cycle 24 was $\sim 20 \%$ lower than that observed during the maximum of solar cycle 23 . The dynamics of the irregularities throughout a solar cycle, as investigated from the estimates of the mean zonal drift velocities, presented a good correlation with the EUV and F10.7 cm solar fluxes. Meanwhile, the seasonal behavior showed that the magnitude of the zonal drift velocities is larger during the December solstice months than during the equinoxes. In terms of modeling, the results for the $\alpha-\mu$ distribution fit quite well with the experimental data and with the temporal characteristics of fading events independently of the solar activity level.
\end{abstract}

Keywords. Electromagnetics (scattering and diffraction) ionosphere (ionospheric irregularities; modeling and forecasting)

\section{Introduction}

The propagation of radio signals in the form of plane waves through a drifting ionosphere with inhomogeneities in the electron density distribution may produce phase and amplitude scintillations (Aarons, 1982; Yeh and Liu, 1982). These scintillations (or fluctuations) are interpreted on the ground as temporal variations in the amplitude and phase of a received power signal. Inhomogeneities in the ionosphere can be produced by plasma-depleted irregularity structures, also known as plasma bubbles. Plasma bubble irregularities develop in the equatorial ionosphere shortly after sunset and rise up above the magnetic equator to altitudes that can exceed $1200 \mathrm{~km}$. The upper height limit above the magnetic equator will define the latitudinal extent in which the bubbles map to off-equatorial regions (Abdu et al., 1983). As the field-aligned plasma bubbles propagate away from the Equator towards low latitudes, they intersect the regions of the equatorial ionization anomaly (EIA). Once the spatial distribution and strength of the scintillations are dominated by the background electron density, the most intense scintillations are expected to occur around $15-20^{\circ}$ from the magnetic equator at latitudes of the crests of the EIA. Moreover, the 
latitudinal variation in the intermediate-scale length (from hundreds of meters to a few kilometers) irregularity spectrum within a plasma bubble may also contribute to strong scintillations near the crests of the EIA (Bhattacharyya et al., 2017).

The climatology, morphology, and dynamics of ionospheric irregularities at the EIA region are among the major research topics studied in ionospheric physics during the past 4 decades (Aarons, 1982; Sobral et al., 2002). Sobral et al. (2002) reported 22 years (1977-1998) of plasma bubble climatology over Cachoeira Paulista $\left(22.4^{\circ} \mathrm{S} ; 45.0^{\circ} \mathrm{W}\right)$ in Brazil, and presented one of the most comprehensive studies of the occurrence of irregularities at the southern crest of the EIA. In the earlier study of Aarons (1982), the author stressed the importance of better knowledge of the characteristics of ionospheric scintillations in order to develop models to minimize the fading problems in Earth-space communications. The work of Aarons (1982) clearly depicts how the scintillation intensities, produced by the smaller-scale irregularity structures coexisting with the plasma bubbles, are maximized in the regions of the Appleton anomaly. More recently, relevant features of ionospheric radio-wave scintillations at the equatorial anomaly region have been extensively investigated for different longitudinal sectors (Spogli et al., 2013; Chatterjee and Chakraborty, 2013; Bhattacharyya et al., 2014; Akala et al., 2015; Cesaroni et al., 2015; Zhang et al., 2015; Srinivasu et al., 2016; Moraes et al., 2017). In the South American sector, particularly for the L-band frequencies, the occurrence characteristics of scintillation-producing irregularities have been demonstrated using ground-based global navigation satellite system (GNSS) receiver networks (e.g., de Paula et al., 2007; Akala et al., 2011; Muella et al., 2013, 2014). The work of de Paula et al. (2007) presented, for one low-latitude station located in the Brazilian east sector, the local time and seasonal occurrence of global positioning system (GPS) L-band scintillations. The study was conducted during the ascending phase of solar cycle 23 (1997-2002) and clearly demonstrated that the scintillation occurrence over Brazil has a seasonal component that departs from other longitude sectors, with the irregularity activity being more intense during the December solstice (summer) months. However, in the western sector of South America, the study of Akala et al. (2011) showed that the highest frequencies and the longest durations of events of scintillations are mostly observed during the March equinox. Common to both longitudinal sectors are the observed least frequencies of occurrence near the June solstice (winter) months. More recently, Muella et al. $(2013,2014)$ investigated the L-band scintillation occurrence over Brazil at latitudes between the north and south crests of the EIA and close to the magnetic equator. The authors showed that the patch duration of scintillations and their occurrence tended to increase with solar activity and that they increased from the magnetic equator toward the crests of the EIA. However, around the southern crest of the EIA the scintillation occurrence during solar maximum years was $\sim 10 \%$ higher than that observed for the northern crest, which suggested a possible influence of the South Atlantic magnetic anomaly (SAMA) on the scintillation activity over South America. However, previous studies in the Brazilian sector were not extended to a quantitative investigation of the long-term climatology of ionospheric scintillation over a station located under the crest of the EIA.

An understanding of the climatology of ionospheric scintillations is best achieved by knowing the spatial and temporal variation in the zonal drift of the irregularities. In the South American sector, the zonal drift of scintillationproducing irregularities has been studied in the last few decades through the detection of VHF geostationary satellite signals (Abdu et al., 1985; Basu et al., 1996; Bhattacharyya et al., 2001; de Paula et al., 2010), from UHF geosynchronous satellite measurements (Valladares et al; 2002; Sheehan and Valladares, 2004), and through an L-band GPS-spaced antenna system (Kil et al., 2000, 2002; Ledvina et al., 2004; Kintner et al., 2004; Muella et al., 2013, 2014). Basu et al. (1996) estimated the zonal drift of the kilometer-scale irregularities causing VHF scintillations above the equatorial site of Ancón (MLAT $1.46^{\circ} \mathrm{N}$ ) in Peru and at the low-latitude station of Agua Verde (MLAT $11.3^{\circ} \mathrm{S}$ ) in Chile. They presented evidence of a latitudinal gradient in the irregularity zonal velocities associated with the vertical shear of the zonal drift in the topside equatorial ionosphere. Also using a VHF system, de Paula et al. (2010) estimated the zonal drift of irregularities at two magnetic conjugate sites in the Brazilian sector and showed that the magnitude of the eastward zonal velocities in the SAMA region may be $\sim 12 \%$ larger than at the conjugate point owing to the weakening of the total magnetic field intensity. Valladares et al. (2002) showed strong correlation in the nighttime variations in UHF scintillation zonal drifts and thermospheric zonal winds, indicating the importance of neutrals in controlling the plasma motion during nighttime. Kil et al. (2002) investigated the latitudinal variations in GPS scintillation activity over Brazil and showed a negative gradient of the irregularity zonal drifts with increasing geomagnetic latitude, which implied decreasing eastward zonal velocities with increasing altitude when it was projected on the $\mathrm{F}$ region in the equatorial plane. Muella et al. (2014) investigated the climatology of irregularity zonal drifts over Cuiabá (MLAT 6.2 ${ }^{\circ} \mathrm{S}$ ) in Brazil from 2000 to 2006 and argued that the magnitude of the zonal velocities might be reduced at the inner regions of the EIA due to the latitudinal variations in the ion drag force. However, in these studies a more complete scenario of the seasonal and solar cycle variation in the zonal drift velocities of scintillation-producing irregularities was not reported for a site located at latitudes of the southern crest of the EIA.

Observational studies of ionospheric scintillations and estimations of their zonal drifts are important to validate the theoretical formulation of scintillations and to mitigate space weather effects on transionospheric radio-wave signals. Physics-based, statistical, and climatological models 
with ingestions of real data have been developed with the aim of describing the physical mechanisms giving rise to scintillations, studying the morphology of scintillations, predicting the strength of radio scintillations as a function of time, latitude, longitude, and geophysical condition, and estimating the severity of scintillation effects on receiver operation (Priyadarshi, 2015, and the references therein). The statistical modeling of scintillations has the advantage of being computationally inexpensive and simpler in terms of the number of input parameters (Humphreys et al., 2009). Hence, higherorder statistical models can be used to understand the impact of amplitude and phase scintillations on GNSS receiver operations, which is important to the technical community involved in the development of mitigation tools useful to the current positioning and navigation technologies. Following the demonstrations of Fremouw et al. (1980), in the work of Hegarty et al. (2001) a scintillation signal model statistically based on the Nakagami- $m$ distribution was developed for the GPS L1-frequency intensity scintillation. Humphreys et al. (2009) assumed the GPS amplitude scintillations following the Rice distribution and proposed a model that can be used to test phase-tracking loops for scintillation robustness evaluation. More recently, Moraes et al. (2014) demonstrated that the $\alpha-\mu$ distribution best describes the variability in the signal amplitude during scintillations and used the same model to evaluate the impact of scintillations on GNSS receiver operations through radio-channel characterization.

In the present study, data recorded by ground-based GPS receivers located under the southern crest of the EIA in the Brazilian sector were used to investigate the occurrence statistics of L-band scintillations. In addition, two GPS receivers were also arranged in a spaced-antenna configuration and aligned magnetically in the east-west direction with the objective of estimating the irregularity zonal drift velocity. We present with these analyses a climatological study of ionospheric scintillations and the dynamics of scintillationproducing irregularities based on $\sim 17$ years of observations at the EIA crest region. Finally, the $\alpha-\mu$ model distribution was used to evaluate first- and second-order statistics of GPS signal amplitude scintillation during periods of different solar activity levels. We use the $\alpha-\mu$ fading model to statistically characterize the amplitude scintillation behavior at different levels of the solar cycle.

\section{Data and method}

\subsection{Scintillation monitoring and irregularity drift estimations}

Ground-based GPS scintillation monitoring systems deployed at the Brazilian low-latitude station of Cachoeira Paulista $\left(22.4^{\circ} \mathrm{S} ; 45.0^{\circ} \mathrm{W}\right.$; dip latitude $\left.16.9^{\circ} \mathrm{S}\right)$ have collected, since September 1997, signal power L1 C/A (1575.42 MHz) amplitude scintillation data samples (at
$50 \mathrm{~Hz}$ ). By using post-processing computer software these scintillation monitors (named SCINTMON), exclusively configured to operate during nighttime, have calculated for each interval of $60 \mathrm{~s}$ the $S_{4}$ amplitude scintillation index for all GPS satellites tracked from 18:00 to 06:00 LT $(\mathrm{UT}=\mathrm{LT}+3 \mathrm{~h})$. The $S_{4}$ index represents the normalized RMS deviation of the received signal power intensity. The large data set of amplitude scintillation measurements at $\mathrm{Ca}$ choeira Paulista allowed us to study the approximately 17year climatology (1997-2014) of ionospheric scintillations at the EIA crest region. In the absence of data at Cachoeira Paulista, we used data from the closest station $(\sim 100 \mathrm{~km})$ of São José dos Campos $\left(23.1^{\circ} \mathrm{S} ; 45.8^{\circ} \mathrm{W}\right.$; dip latitude $\left.17.3^{\circ} \mathrm{S}\right)$ to complement the analysis. The same type of GPS scintillation monitor is installed at both stations and it has been previously described by Beach and Kintner (2001).

The occurrence statistics of the GPS L1-frequency amplitude scintillations were analyzed for the observatory of Cachoeira Paulista during the period of September 1997November 2014. This period includes most of solar cycle 23 (that occurred between May 1996 and October 2008) and solar cycle 24 (since around November 2008). The general influence on the climatology of scintillations of the long sunspot cycle 23, the unusual depth and duration of the last solar minimum (2007-2009), and the comparatively weaker solar cycle 24 is briefly analyzed. The possible influence of the secular variation in the dip latitude of Cachoeira Paulista on the scintillation climatology due to the motion of the magnetic dip equator was also discussed. For the station of $\mathrm{Ca}$ choeira Paulista, about 6000 nights of L1 amplitude scintillation data were used in the analysis. Only data from geomagnetically quiet days with daily (3-hourly planetary) $\Sigma \mathrm{Kp}$ index $<24$ were considered in the climatologic study.

At the site of Cachoeira Paulista two SCINTMON receivers also operated simultaneously from 1998 to 2007. The antennas of the scintillation monitors were separated by a distance of $55 \mathrm{~m}$ along the magnetic east-west direction. By measuring the amplitude scintillation patterns, the eastwest drifts of the irregularities across the signal path from the satellites to the spaced SCINTMON antennas were inferred by the ground receivers. This configuration was used to measure the zonal scintillation pattern velocity $\left(V_{\text {scint }}\right)$ in the coordinate frame of the two spaced antenna receivers. The values of $V_{\text {scint }}$ were obtained from the cross-correlation functions of the data measured by the two spaced receivers and for all scintillating satellite signals. The estimations were limited to measurements made from satellites with an elevation angle higher than $40^{\circ}$ and for a scintillation index $S_{4}>0.2$. This threshold of the $S_{4}$ index may be considered to be above the level of noise and multipath effects. The crosscorrelation function $C(\tau)$ between the time sequences $S_{1}$ and $S_{2}$ of two signal intensities is given as (Kil et al., 2000) 
$C(\tau)=\frac{\sum_{k} S_{1}\left(t_{k}\right) S_{2}\left(t_{k}-\tau\right)}{\sqrt{\sum_{k} S_{1}^{2}\left(t_{k}\right) \sum_{k} S_{2}^{2}\left(t_{k}-\tau\right)}}$,

where $k$ is an index into the time series and $\tau$ is the time lag with optimal values that occur when it maximizes $C(\tau)$. In order to reduce any effect of the apparent velocities in the $V_{\text {scint }}$ calculations, as detailed by Kil et al. (2002) and Muella et al. (2014), we considered in the analysis a high threshold of 0.9 for the peak cross-correlation. Then, the mean ionospheric irregularity zonal drift velocities $\left(V_{\text {zonal }}\right)$ are inferred by averaging the $V_{\text {scint }}$ velocities measured from the various scintillating GPS satellite signals. The method used here to estimate $V_{\text {zonal }}$ was primarily described in the study of Ledvina et al. (2004), and a modified form was applied more recently in the studies of Muella et al. (2013, 2014). To estimate $V_{\text {zonal }}$ we used the following relation:

$$
\begin{aligned}
V_{\mathrm{zonal}} & =\frac{h_{\mathrm{sat}}-h_{\mathrm{ipp}}}{h_{\mathrm{sat}}}\left(V_{\text {scint }}\right) \\
& +\frac{h_{\mathrm{ipp}}}{h_{\text {sat }}}\left[V_{\text {sat } x}+\left(q_{y} / q_{x}\right) V_{\text {sat } y}+\left(q_{z} / q_{x}\right) V_{\mathrm{sat} z}\right],
\end{aligned}
$$

where $h_{\text {sat }}$ is the satellite height, $h_{\text {ipp }}$ denotes the mean scattering height of the irregularities (assumed as $350 \mathrm{~km}$ ) above the receivers' horizontal plane, $V_{\text {sat } x}, V_{\text {sat } y}$, and $V_{\text {satz }}$ respectively represent the zonal, meridional, and vertical components of the satellite velocity, and the ratios $\left(q_{y} / q_{x}\right)$ and $\left(q_{z} / q_{x}\right)$ are the mapping factors that rotate all vectors into the receivers' coordinate system as a function of the satellite zenith and azimuth angles and the magnetic dip and declination angles of the magnetic field at the $h_{\mathrm{ipp}}$. In this study, the mean zonal drift velocities ( $\left.V_{\text {zonal }}\right)$ of the scintillationproducing irregularities were inferred during 281 geomagnetically quiet nights. The $V_{\text {zonal }}$ values were obtained during the December solstice (summer) months (1999-2001; 2003$2007)$ and during the equinoctial months $(1999 ; 2001 ; 2003-$ 2005).

\subsection{Ionospheric fading model}

The $S_{4}$ index is the indicator of the severity of the amplitude scintillation and is widely used to quantify the severity of ionospheric scintillation. Another parameter, which has become of interest in recent studies (Humphreys et al., 2010; Carrano and Groves, 2010), is the decorrelation time $\tau_{0}$. This parameter provides temporal information about scintillation and may be interpreted as the indicator of the fading rate, defined as the time lag at which the autocorrelation function $\left(A_{r}\right)$ of amplitude scintillation falls off by $\exp (-1)$ from its maximum (zero lag) value. Thus

$A_{r}(\tau)=\frac{E[(r(t)-z)(r(t+\tau)-z)]}{\sigma_{r}^{2}}$,

where $z$ and $\sigma_{r}^{2}$ are the mean and variance values of the amplitude $r$, respectively, and $E($.) denotes the expected value operator. The $\tau_{0}$ is obtained from $A_{r}\left(\tau_{0}\right) / A_{r}(0)=\exp (-1)$. Examples of the variability in the decorrelation time as computed from GPS L1 amplitude scintillation measurements can be found in Fig. 2 of the work of Oliveira et al. (2014). Additionally to the fading rate, the $\tau_{0}$ parameter may be used to characterize the turbulent ionospheric medium (Carrano et al., 2012) and to predict GPS receiver cycle slipping rates (Humphreys et al., 2010). For example, in Moraes et al. (2011), the typical values of probability of cycle slip for GPS users at low latitudes under amplitude scintillation conditions were up to $35 \%$. Therefore, the evaluation of $\tau_{0}$ is important to describe the receiver performance under scintillation effects and to characterize the ionospheric medium.

Moraes et al. (2012) proposed the model used in this work for the transionospheric radio-wave scintillations at the GPS L1 frequency. This signal fading model is based on a $\alpha-\mu$ distribution for intensity scintillation. According to Yacoub (2007), one advantage of the physical model for the $\alpha-\mu$ distribution is the fact that it takes into account the inhomogeneities of the propagation medium. Hence, it can be considered a general fading model in which the received radio signals are composed of clusters of multipath waves assumed to be scattered with identical powers. Thus, we take this advantage of the model by associating the $\alpha-\mu$ parameters with the physical fading of the ionospheric scintillation phenomena. In this study, we initially used the $\alpha-\mu$ signal model to investigate the first-order statistics of the amplitude scintillation phenomena.

According to Moraes et al. $(2012,2014)$, the $\alpha-\mu$ probability density function of the normalized amplitude envelope $r$ is given by

$f(r)=\frac{\alpha r^{\alpha \mu-1}}{\xi^{\alpha \mu / 2} \Gamma(\mu)} \exp \left(-\frac{r^{\alpha}}{\xi^{\alpha / 2}}\right), \quad \xi=\frac{\Gamma(\mu)}{\Gamma(\mu+2 / \alpha)}$,

where $\Gamma($.$) is the gamma function, the parameter \mu$ denotes the number of multipath components in the propagation environment, and the power parameter $\alpha$ denotes the modulus of the sum of those clusters that results in the envelope that propagates in the nonhomogeneous environment. A more detailed description of the physical properties represented by the $\alpha-\mu$ parameters can be found in the work of Yacoub (2007) and Moraes et al. (2012).

A second advantage in the use of the $\alpha-\mu$ distribution represented by Eq. (4) is the fact that, depending on the values of the parameters $\alpha$ and $\mu$, it may become a Weibull, an exponential, a Rayleigh, a one-sided Gaussian, or a Nakagami distribution. Since the $\alpha-\mu$ model has two parameters that are directly described by the physical properties of the ionospheric medium, it becomes more flexible and mathematically tractable, ensuring much better agreement with $S_{4}$ data whether compared to the popular Nakagami- $m$ or Rice distributions (e.g., Moraes et al., 2012).

The $\alpha-\mu$ pair of parameters can be estimated from the equality that involves the moments of $\alpha-\mu$ amplitude enve- 
lope given by Yacoub (2007):

$$
\begin{aligned}
& \frac{E^{2}\left(r^{\beta}\right)}{E\left(r^{2 \beta}\right)-E^{2}\left(r^{\beta}\right)}= \\
& \frac{\Gamma^{2}(\mu+\beta / \alpha)}{\Gamma(\mu) \Gamma(\mu+2 \beta / \alpha)-\Gamma^{2}(\mu+\beta / \alpha)} .
\end{aligned}
$$

Finally, the values of the $\alpha-\mu$ pair that best represent the amplitude distribution in the scintillation index $S_{4}$ can be obtained from the following relation:

$S_{4}^{2}=\frac{\Gamma(\mu) \Gamma(\mu+4 / \alpha)-\Gamma^{2}(\mu+2 / \alpha)}{\Gamma^{2}(\mu+2 / \alpha)}$.

Another advantage of the $\alpha-\mu$ model is the fact that it can also be used to understand the impact of the irregularities producing scintillations on GPS receiver operations. In this case, second-order statistics may be derived from the $\alpha-\mu$ model and then used to calculate GPS radio-channel characterization, such as the average fading duration (AFD) and the level crossing rate (LCR). Fading is a well-known phenomenon caused by the superposition of two or more versions of the transmitted signal that may result in either constructive or destructive interferences. These effects are interpreted as changes in the amplitude envelope of the received power signal. Thus, the analysis of the AFD and LCR parameters are devoted here to the temporal characteristics of these fading events. Moreover, the AFD and LCR are important in receiver design and model. The former parameter indicates the average amount of time that the amplitude envelope of the received power signal spends below a certain threshold, whereas the latter provides the average number of times within an observation period that the envelope of a fading signal crosses a certain level in the downward or upward direction (e.g., Moraes et al., 2014).

According to Yacoub (2007) the AFD (in seconds) for the $\alpha-\mu$ distribution is given by

$$
T_{R}(r)=\frac{\sqrt{2 \pi} \Gamma\left(\mu, \mu \rho^{\alpha}\right) \exp \left(\mu \rho^{\alpha}\right)}{\omega \mu^{\mu-0.5} \rho^{\alpha(\mu-0.5)}}
$$

and the LCR (in crossings per second) for the $\alpha-\mu$ distribution is obtained from

$N_{R}(r)=\frac{\omega \mu^{\mu-0.5} \rho^{\alpha(\mu-0.5)}}{\sqrt{2 \pi} \Gamma(\mu) \exp \left(\mu \rho^{\alpha}\right)}$,

where $\omega$ is an empirical parameter used as an offset adjustment of LCR and AFD function and was introduced by Yacoub (2007). In the present work we used $\omega=2$ for the cases of solar maximum and moderate solar activity and $\omega=3$ for the cases of solar minimum. The values of $\omega$ used here are those that provided the minimum absolute error deviation and were based on the previous work (Table 2 and Eq. 13) of Moraes et al. (2014). As we are computing the crossing rate for $E\left[r^{2}\right]=1$, the scale factor $\rho$ for both LCR and AFD can be found as

$\rho=r \sqrt{\frac{\Gamma(\mu+2 / \alpha)}{\Gamma(\mu)}} \mu^{-1 / \alpha}$,

where $r$ in Eqs. (7), (8), and (9) is the value of the normalized amplitude envelope as defined in Eq. (4).

The complete outlining of the $\alpha-\mu$ distribution for scintillations and for the AFD and LCR calculations can be found in the work of Moraes et al. $(2012,2014)$, and therefore their full mathematical description will be limited to the equations presented above. In the present work, the scintillations at the low-latitude station of Cachoeira Paulista are modeled for different values of the $S_{4}$ index (from 0.4 to 0.9 ) and during periods that represent different phases of the solar cycle (solar maximum, solar minimum, and intermediate level). Finally, second-order statistics are used to evaluate the AFD and LCR parameters during cases of different solar activity levels.

\section{Results and discussion}

\subsection{Ionospheric scintillation climatology}

The panels in Fig. 1 show the percentage of occurrence of GPS L1-amplitude scintillations, as observed for the low-latitude station of Cachoeira Paulista for the period of September 1997-November 2014. The plots from Fig. 1 provide a general picture of the climatology of ionospheric scintillations over a station located in the southern crest of the EIA. The nocturnal occurrence statistics are presented as a function of universal time ( $\mathrm{UT}=\mathrm{LT}+3 \mathrm{~h}$ ) and considering two distinct thresholds of the $S_{4}$ scintillation index. Figure 1a shows the occurrence of scintillation for $S_{4}>0.2$, while Fig. $1 \mathrm{~b}$ is valid for the threshold of $S_{4}>0.5$. Data were not available for May 1999, the beginning of September 1999, and January 2001-March 2001. In the statistics data were only considered from satellites with an elevation angle higher than $40^{\circ}$. The variation in solar activity over the period analyzed here can be visualized in Fig. 1c, as represented by the monthly mean variation in the solar radio flux in $10.7 \mathrm{~cm}$ (F10.7 index). As shown in Fig. 1, we can observe how the scintillation activity changes with time, month, season, year, and solar activity level.

The patches of the highest occurrence of scintillations were observed in Fig. 1a from 23:00 to 04:00 UT (or 20:00 to 01:00 LT) for the threshold level of $S_{4}>0.2$ and from 23:00 UT until around midnight in Fig. 1b for the cases when $S_{4}>0.5$. The scintillations also occur predominantly in the period of September-March and are generally more intense around the December solstice (summer) months when the longitude of Cachoeira Paulista is in close alignment between the sunset terminator and the magnetic meridian due to the large westward magnetic declination angle of this region. A 


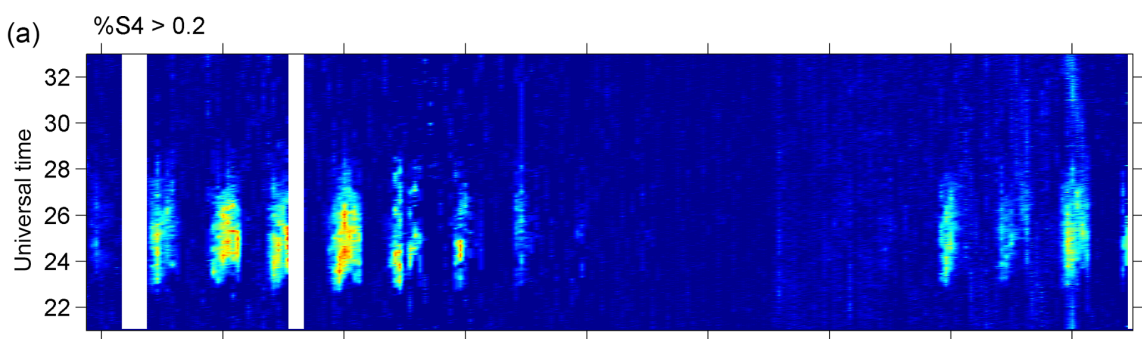

(b) $\% \mathrm{~S} 4>0.5$

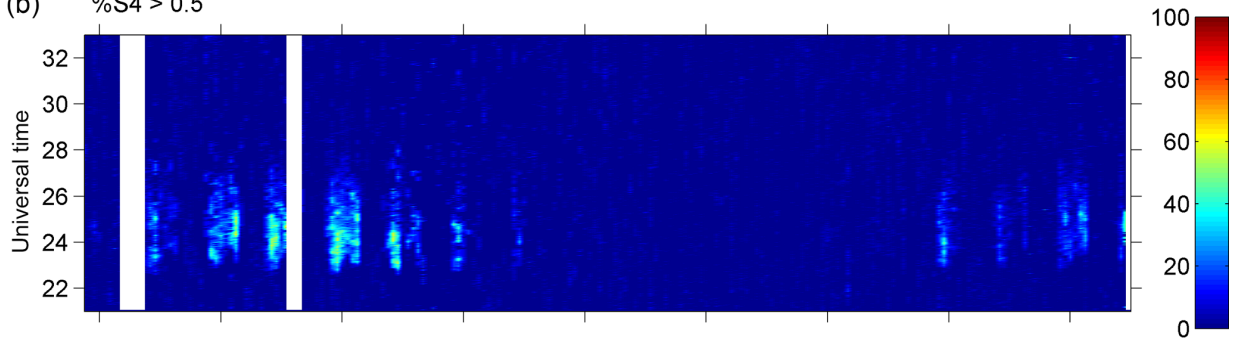

(c)

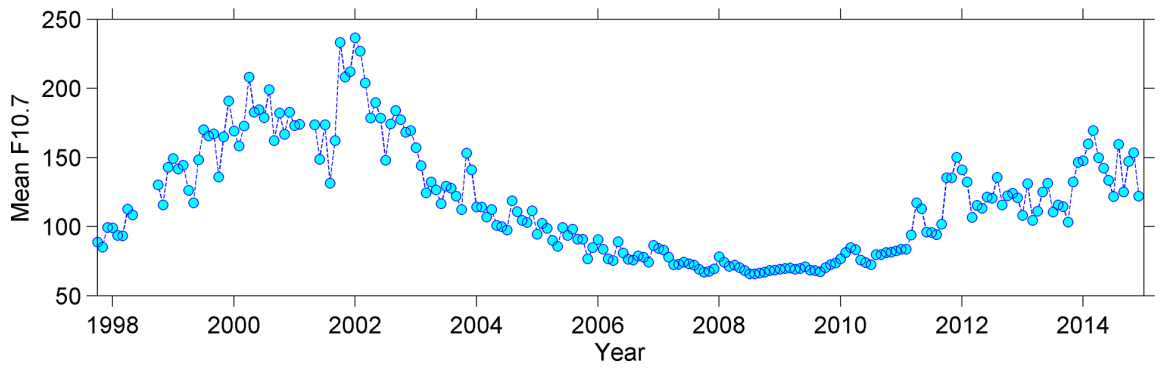

Figure 1. Percentage of scintillation occurrence at Cachoeira Paulista as a function of Universal Time (UT $=\mathrm{LT}+3 \mathrm{~h})$ from September 1997 to November 2014 for two threshold levels of the $S_{4}$ scintillation index; $S_{4}>0.2$ in panel (a) and $S_{4}>0.5$ in panel (b). The monthly mean $\mathrm{F} 10.7 \mathrm{~cm}$ solar flux is shown in panel (c).

broad minimum in the seasonal occurrence of ionospheric scintillations is observed in the June solstice (winter) months. An important aspect that can be immediately seen in Fig. 1 is the variation in the percentage of scintillation occurrence during most of solar cycle 23 (that started in May 1996). The maximum activity period of solar cycle 23 occurred in 2000-2002. As the statistical series of scintillation begins at the end of 1997, the increase in the scintillation occurrence during the ascending phase of solar cycle 23 can clearly be observed in Fig. 1a and b. The maximum percentages of occurrence of about 80 and $50 \%$ were observed over Cachoeira Paulista around December 2001 and January-February 2002, respectively, for the threshold levels of $S_{4}>0.2$ and $S_{4}>0.5$. Scintillation intensity is known to be a function of both the electron density deviation of the irregularity $(\Delta N)$ and the thickness of the irregularity layer. In years of high solar flux, the ionosphere becomes thicker and the background electron density increases at latitudes of the EIA. Thus, large levels of $\Delta N$ are expected to be formed around the solar maximum years. Consequently, much stronger scintillations are likely to appear in the latitudes surrounding the crest of the
EIA, under which the site of Cachoeira Paulista is located. The largest scintillations at latitudes of the EIA also tend to be associated with regions of intense TEC gradients (Muella et al., 2013, 2014). In addition, as the large-scale bubbles map down along geomagnetic field lines to off-equatorial latitudes, the spectrum of the intermediate-scale irregularities within the bubbles tends to become shallower near the F-region peak. This factor, based on the recent study of Bhattacharyya et al. (2017), also contributes to the strong L-band scintillations observed near the crest of the EIA, particularly in years of high solar activity and during the December solstice months in the longitude of Cachoeira Paulista.

Figure 1 also shows that the occurrence of scintillation started to subside with the decline in solar activity. The descending phase of cycle 23 extended from 2002 until around October-November 2009, which was historically considered the solar cycle with the longest decline phase since the first official records. Despite the longevity of the descending phase, the occurrence of strong levels of scintillation $\left(S_{4}>0.5\right)$ seemed to be extremely reduced as early as 2006 , while for the overall scintillation activity a drastic reduction 
started in 2007 as revealed in Fig. 1a. Another important effect on the occurrence of scintillations that appears clearly hallmarked in Fig. 1a and b occurred in the period of December 2002-February 2003. There is a sudden drop in the frequency of the occurrence of scintillations, which was recently attributed by de Paula et al. (2015) to a sudden stratospheric warming (SSW) event. This signature of scintillation weakening by SSW observed at the low-latitude station of Cachoeira Paulista can be associated with the following: (a) a reduction in the growth rate of the plasma instability process during post-sunset hours owing to the decrease in the equatorial ionospheric vertical drifts; (b) the presence of an opposing thermospheric wind induced by the SSW in the Northern Hemisphere that possibly modified the flux-tubeintegrated conductivities, leading to the suppression of the secondary instability processes that generate smaller-scale irregularities; and (c) an anomalous distribution of the ionospheric plasma density around the southern crest of the EIA during the SSW event, which possibly affected the scintillation activity over Cachoeira Paulista. Some weakening is also evident in Fig. 1b around January and February of the years 1999, 2000, and 2002, possibly associated with SSW events, which still needs further investigation.

Another marked effect depicted in Fig. 1a is related to the pronounced decrease in the overall occurrence of scintillations during the period of 2007-2009. This diminishment is associated with the unusual solar minimum that hit bottom in 2008. This deep solar minimum period was related to the lowest values of sunspot numbers registered in about 100 years (Hady, 2013) and an anomalous reduction in solar extreme ultraviolet (EUV) irradiance (Solomon et al., 2010). According to previous studies, during the anomalous minimum in the transition of solar cycles 23-24 the global ionosphere became more contracted in height than other previous solar minimum conditions, the base altitude of the $\mathrm{F}$ layer was the lowest, the ionospheric electron density was unusually low (Liu et al., 2011), and the fountain effect was suppressed (Santos et al., 2013). Thus, the reduced ambient ionization at the EIA during the deep solar minimum period throughout the years 2007-2009 certainly played an important role in the weakening of the scintillation activity over Cachoeira Paulista.

The present solar cycle 24 started to increase slowly after October 2008 and just around the middle of 2010 the monthly values of $10.7 \mathrm{~cm}$ radio flux exceeded $80 \mathrm{sfu}$. The ascending phase of solar cycle 24 lasted until around April 2014 when it attained its maximum phase; it is currently considered by solar physicists as the weakest solar cycle in more than a century. According to Solanki et al. (2002), the length of a solar cycle can be considered a good predictor for the maximum sunspot number in the coming cycle. They argued that as solar cycle 23 was long with a delayed descending phase, the memory of its length by the solar dynamo was carried into the next cycle, and consequently it would be expected that the present solar cycle 24 will have a small number of sunspots. The consequence of this weak solar cycle in the scintillation occurrence can be clearly seen in Fig. 1. The maximum frequency of occurrence of $\sim 60 \%$ was observed in 2014 for $S_{4}>0.2$ and $\sim 45 \%$ in 2014 for the highest levels of scintillation when $S_{4}>0.5$. This represents a reduction of approximately $20 \%$ in comparison to the solar maximum of cycle 23 during the season of higher occurrence. Associated with this weakest solar cycle is a reduction in the solar EUV flux and lower atomic oxygen densities, which led to a reduction in the ionospheric densities at the EIA region. The measurements of global average total electron content reported by Hao et al. (2014) confirm the fact that during the first half of solar cycle 24 the ionosphere was weakly ionized in comparison to the previous cycle 23. Also as a consequence of the reduction in the EUV flux, a decrease in the E-region conductivity leading to decay in the development of equatorial F-region $\boldsymbol{E} \times \boldsymbol{B}$ drifts is expected. Thus, the generation of equatorial plasma bubble irregularities and the distribution of ionospheric ionization at the crests of the EIA have possibly been affected during solar cycle 24 . As scintillations require a significant plasma density and strong electron density fluctuations to occur, the reduced ambient ionization accompanied with changes in the strength and position of the southern crest of the EIA are probably limiting the scintillations to levels of comparatively weaker intensities.

As mentioned before, the latitudinal extent of the equatorial plasma bubbles is crucial in determining the scintillation activity around the anomaly crest. This extent depends on the upper height limit attained by the bubble above the magnetic dip equator. Also, the strength of nocturnal scintillations seems to be well correlated with the resurgence of EIA driven by pre-reversal enhancement $\boldsymbol{E} \times \boldsymbol{B}$ drift and the location of the EIA crest (Chatterjee and Chakraborty, 2013). These factors are known to be intimately related to the location of the dip equator. According to Rangarajan and Barreto (2000), in the American zone the dip equator is moving westward at a rate of $\sim 0.22^{\circ}$ per year and in the Brazilian longitudinal sector an unmistakable northward drift is also noteworthy due to the configuration of the magnetic equator. This means that in addition to the solar cycle dependence, the occurrence climatology of scintillations depicted in Fig. 1 is possibly under the influence of changes in the dip latitude of Cachoeira Paulista over $\sim 17$ years. For example, Fig. 2 presents the variation in the dip latitude of Cachoeira Paulista (line with circles) during the period of 1997-2014 as calculated from the International Geomagnetic Reference Field (IGRF) model. The results revealed a change in the dip latitude from $\sim 16.5^{\circ} \mathrm{S}$ in 1997 to $\sim 19.7^{\circ} \mathrm{S}$ in 2014 . The plot inserted in the upper right corner of Fig. 2 also shows how the dip equator in the longitude range of the magnetic meridian of Cachoeira Paulista moved in relation to the geographic Equator in 1997 (dashed line) and in 2014 (solid line). Hence, it is possible that the percentage of scintillation occurrence observed in Fig. 1 is also being modulated 


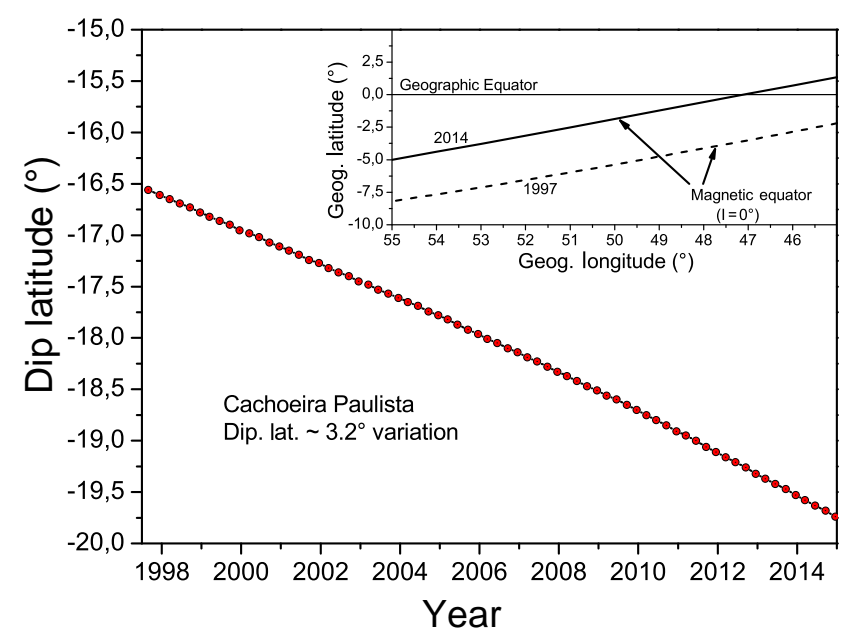

Figure 2. Variations in the dip latitude of Cachoeira Paulista (line with circles) and in the magnetic dip equator (panel in the top corner) during the period from 1997 to 2014.

by migratory changes in the location of the magnetic dip equator and with the increase in the dip latitude of Cachoeira Paulista. For example, the field line apex over the dip equator that maps to the $\mathrm{F}$ region at the latitudes of Cachoeira Paulista increased from around $850-900 \mathrm{~km}$ in 1997 to over $1100 \mathrm{~km}$ in 2014. This means that the site of Cachoeira Paulista that was under the crest of the EIA in 1997 is now located further along the poleward edge of the southern EIA region. Consequently, the bubbles have to extend somewhat beyond the EIA crest to be detected over Cachoeira Paulista, which also possibly leads to comparatively fewer occurrences of scintillation around the solar maximum year of 2014.

\subsection{Ionospheric irregularity zonal drift velocities}

To infer the average zonal drift velocities of the ionospheric irregularities, the amplitude fluctuations registered in the measurements of the signal power intensity by the ground receivers were arranged for two seasonal periods, equinoxes (March-April and September-October) and December solstice (summer) months (November-February). No calculations were performed during the June solstice (winter) months due to the much reduced occurrence of scintillations through that season. As mentioned in Sect. 2.1, only data from geomagnetic quiet days were used in the zonal drift estimations. The irregularity zonal drift estimations here are based on 207 nights during the summer months (years 1999-2001 and 2003-2007) and 74 nights during the equinoxes (years 1999, 2001, and 2003-2005). The panels in Figs. 3 and 4 respectively show the nocturnal variations in the mean zonal drift velocities (positive eastward) during the equinoxes and December solstice months. As shown in the plots, the irregularity drift velocities were averaged for each $30 \mathrm{~min}$ bin and plotted here as a function of the local time. The number of drift estimates for each bin is presented close to the respective symbols. The standard deviations of the inferred drift velocities were plotted as vertical bars and are shown in the graphs.

As can be seen in Figs. 3 and 4, the prevailing characteristic of the mean irregularity zonal drift velocities over Cachoeira Paulista during the equinoxes and December solstice months is the reduction in the amplitude of the eastward velocities with the progression of night. This behavior is in agreement with earlier observations reported at equatorial and low-latitude regions (e.g., Otsuka et al., 2006; Muella et al., 2013, 2014; Liu et al., 2015). According to theoretical formulations, this is a direct result of the post-sunset weakening of the vertical electric fields mapped to off-equatorial latitudes. However, we further note that the drift velocities may present clearly distinct time, seasonal, and solar cycle variations. For example, in Fig. 3c the irregularity zonal velocity during the equinoxes of the year 2005 showed an increase from the early evening of $\sim 70 \mathrm{~m} \mathrm{~s}^{-1}$ until its maximum of $\sim 160 \mathrm{~m} \mathrm{~s}^{-1}$ at around 23:00 LT, which rapidly decreased from then on. Before attaining its maximum value, a deep reduction in the zonal drift with a magnitude of $\sim 110 \mathrm{~m} \mathrm{~s}^{-1}$ was observed at around 22:00 LT. Such behavior was not observed in a similar way during the equinoxes of the years 1999 to 2004 when the maximum velocities were observed earlier, at around 20:00-20:30 LT, followed by a decrease toward the later hours of the night. In contrast, the irregularity zonal drifts estimated during the December solstice months of the years 2004 to 2007 presented quite similar behavior to that observed during the equinoxes of the year 2005. The marked differences are the comparatively larger mean velocities during early evening (from $\sim 100$ to $120 \mathrm{~m} \mathrm{~s}^{-1}$ ) followed by a brief initial increase until reaching the peak velocities between 21:00 and 22:00 LT.

Table 1 summarizes the averaged irregularity zonal drifts $\left(\overline{V_{\text {zonal }}}\right)$ during nighttime for each seasonal period throughout the years 1999-2007, the maximum velocity of the nocturnal variations in mean zonal drifts $\left(V_{\max }\right)$, and its time of occurrence $\left(t_{\max }\right)$ as taken from the plots of Figs. 3 and 4 , and the average values of the F10.7 index (in units of $10^{-22} \mathrm{~W} \mathrm{~m}^{-2} \mathrm{~Hz}^{-1}$ ) during the days used to compute the mean irregularity drifts. A more detailed inspection of the results presented in Figs. 3 and 4 and Table 1 reveals that the average nocturnal irregularity drifts during the December solstice months are larger than during the equinoctial periods. They are more pronounced in the years close to solar maximum (mainly between 2001 and 2003) and tend to decrease in the years of moderate solar cycles (2004 and 2005). Considering only a particular season, it is possible to observe that $\overline{V_{\text {zonal }}}$ for the December solstice period is larger in the years of high solar flux units (sfu) and tends to decrease toward solar minimum. However, during the years of moderate solar activity in the ascending and descending phases of the solar cycle, the values of $\overline{V_{\text {zonal }}}$ seem not to change significantly. Conversely, for the equinoxes the dependence with 
(a)

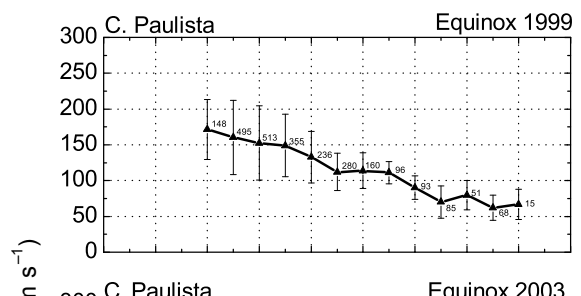

(b)
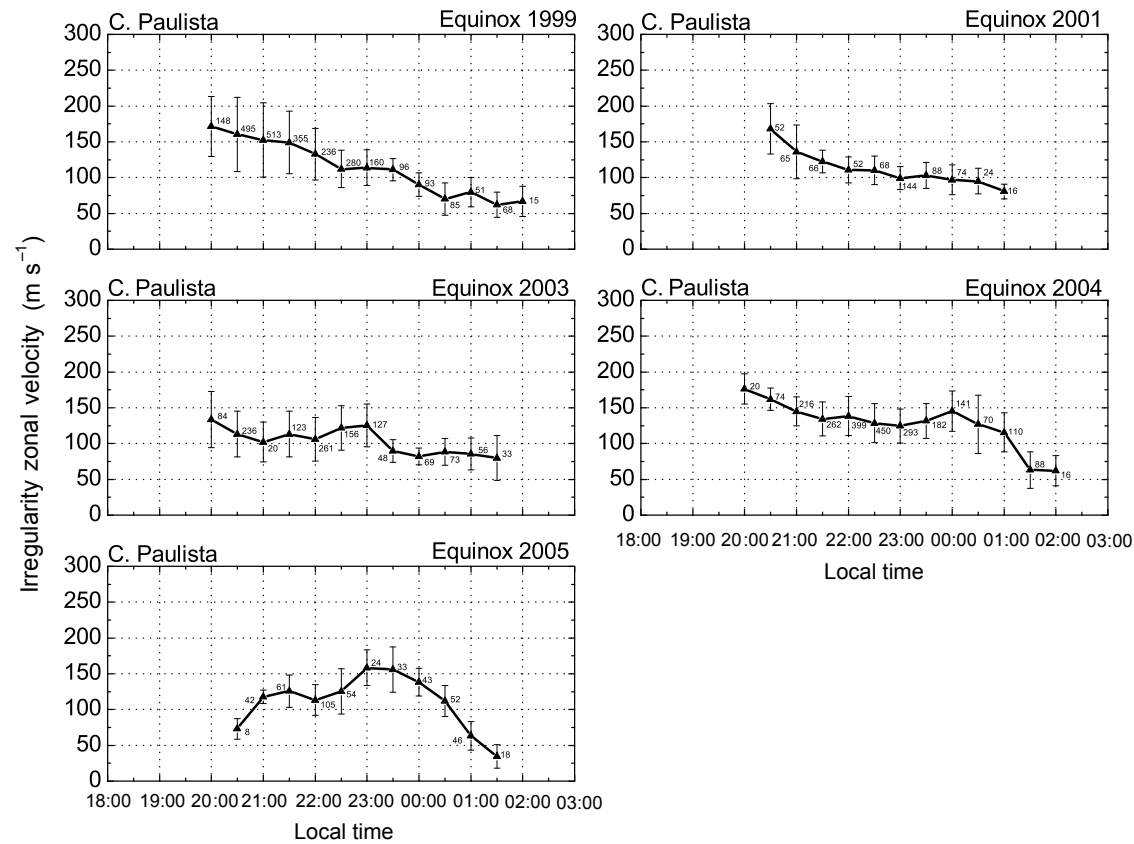

(c)

Figure 3. Nocturnal variations in the irregularity zonal (eastward) drift velocities estimated at Cachoeira Paulista during the equinoctial periods of the years 1999 and 2001 (a), 2003 and 2004 (b), and 2005 (c).

solar flux is not as evident as observed for the December solstice months.

It is well known that at low latitudes the field-linemapped ionospheric vertical electric field is responsible for the zonal motions of the ambient plasma (Haerendel et al., 1992). Since the maximum contribution of the scintillationproducing irregularities occurs at the heights of peak electron density, any change in the evening peak of the F region is expect to affect the dynamic evolution of these irregularities. Theoretical formulations have predicted that the nighttime eastward irregularity drift, which can be considered equivalent to the background plasma drift, depends essentially on a ratio of flux-tube-integrated Pedersen conductivity weighted by the F-region zonal neutral wind velocity (Anderson and Mendillo, 1983; Haerendel et al., 1992; Eccles, 1998; Santos et al., 2016). Thus, the years with larger mean irregularity zonal velocities during the December solstice (summer) months over Cachoeira Paulista are possibly associated with a stronger vertical polarization electric field owing to a larger thermospheric zonal wind, which then drives the irregularities zonally. Moreover, at the latitudes of Cachoeira Paulista the ion drag forces imposed by the enhanced electron density structures of the EIA may also play an important role in neutral wind dynamics (Martinis et al., 2003; Muella et al., 2014), which in turn could affect the plasma dynamics and the irregularities in them. It is worth mentioning that the zonal drifts estimated here only over Cachoeira Paulista cannot be used to infer the altitude variation in the vertical elec- tric fields; simultaneous measurements at different latitudes along the same magnetic meridian would be necessary.

In Fig. 5 the mean values of the irregularity zonal drift velocity (between 22:00 and 24:00 LT) throughout the entire period analyzed in this study were used to correlate with the daily mean values of the F10.7 index (Fig. 5b) and the daily mean values of full solar disk EUV flux (in units of photons $\mathrm{cm}^{-2} \mathrm{~s}^{-1}$ ) at $1 \mathrm{AU}$ (wavelength range of $0.1-50 \mathrm{~nm}$ ) obtained from the SEM sensor aboard the SOHO spacecraft (Fig. 5a). We have selected the period of 22:00-24:00 LT because throughout this time the scintillation-producing irregularities can be considered for practical purposes to drift at comparable velocities with the background plasma (Kil et al., 2000, 2002; Engavale et al., 2005). Before 22:00 LT, due to the presence of perturbation electric fields associated with the Rayleigh-Taylor instability, the irregularities are still growing and the values of $V_{\text {zonal }}$ may present great variability (Bhattacharyya et al., 2001; Engavale et al., 2005), whereas after 24:00 LT the scintillation-producing irregularities start to decay faster by cross-field diffusion (Basu et al., 1978). The tendency for the irregularity drift velocities to increase with increasing EUV and F10.7 cm solar fluxes can clearly be seen in the plots of Fig. 5. Such an increase in $V_{\text {zonal }}$ is also in agreement with the observations of Engavale et al. (2005) and Fejer et al. (2005), who respectively reported pre-midnight irregularity drift and zonal drift in the equatorial F-region plasma as increasing with the solar flux.

Figure 5 also shows that the cross-correlation coefficients (linear fit) for both EUV flux $(R=0.65)$ and the F10.7 in- 

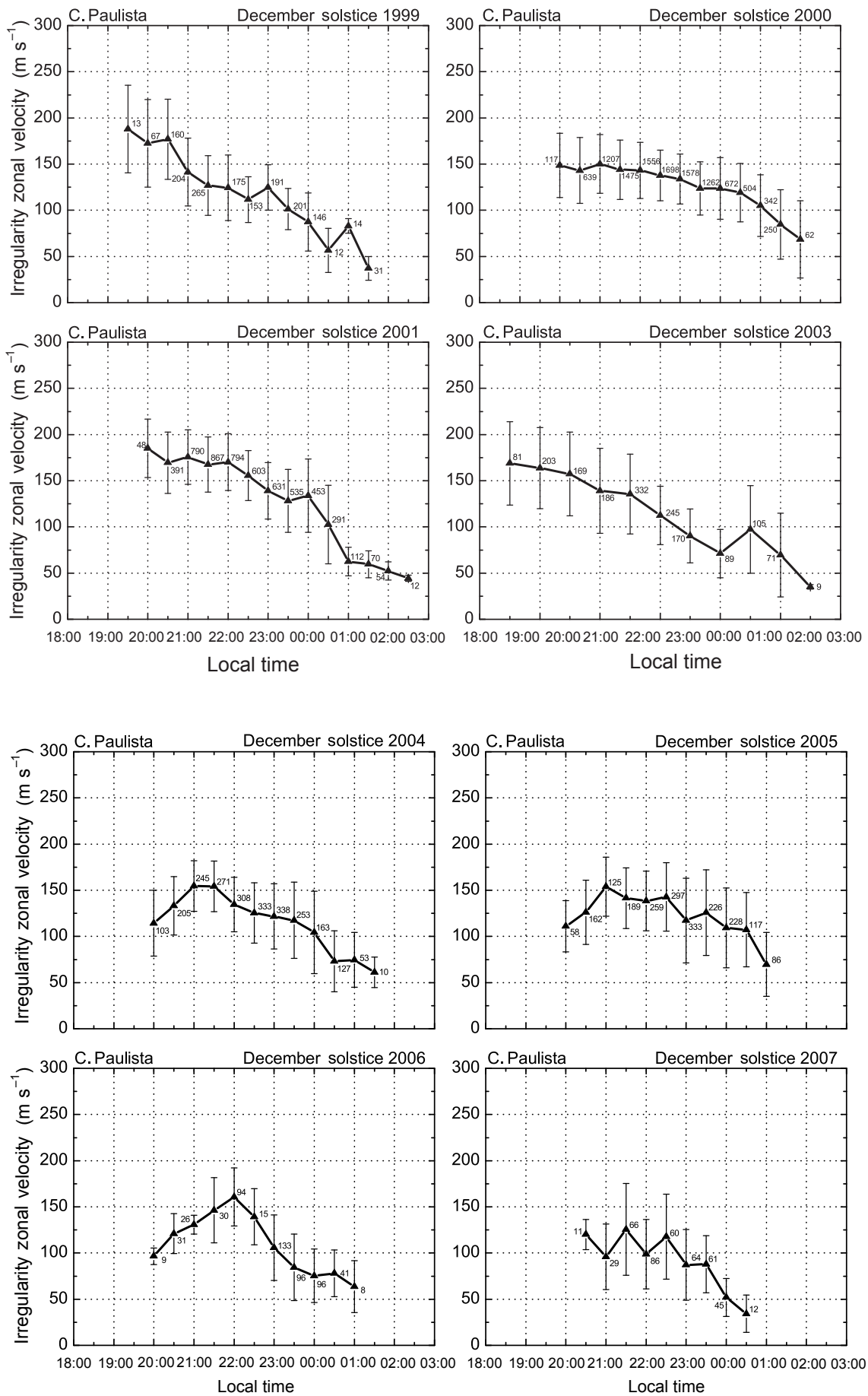

Figure 4. Nocturnal variations in the irregularity zonal drift velocities estimated at Cachoeira Paulista during the December solstice months of the years 1999-2001 and 2003-2007 (from top to bottom panels).

dex $(R=0.70)$ are quite similar and can be used to investigate solar cycle effects on the irregularity drift velocity. The mostly marked difference is depicted in Fig. 5b; the tendency for $V_{\text {zonal }}$ to become nonlinear as the F10.7 index values increase can clearly be seen from the polynomial fit (red line). However, for $V_{\text {zonal }}$ versus the F10.7 index, the parabolic fit
$(R=0.51)$ also suggests that the saturation level of the irregularity drift velocities may exist for higher flux levels. We may note for the $V_{\text {zonal }}$ versus EUV case (Fig. 5a) that the relationship is strongly linear, with the parabolic curve adjusting moderately $(R=0.42)$. A direct correlation between EUV flux and the F10.7 index has been reported by Santos et 
Table 1. Averaged irregularity zonal drifts $\left(\overline{V_{\text {zonal }}}\right)$, time of occurrence $\left(t_{\max }\right)$ of maximum velocity of the nocturnal variations in mean zonal drifts $\left(V_{\max }\right)$, and the average values of the F10.7 index (in units of $10^{-22} \mathrm{~W} \mathrm{~m}^{-2} \mathrm{~Hz}^{-1}$ ) during the days used to compute the seasonal variations in irregularity zonal drift velocities throughout the years 1998-2007.

\begin{tabular}{lrrrr}
\hline Equinoxes & $\overline{\mathrm{F} 10.7}$ & $\overline{V_{\text {zonal }}}\left(\mathrm{m} \mathrm{s}^{-1}\right)$ & $V_{\max }\left(\mathrm{m} \mathrm{s}^{-1}\right)$ & $t_{\max }(\mathrm{LT})$ \\
\hline 1999 & 170.8 & 135.2 & 171.5 & $20: 00$ \\
2003 & 157.7 & 112.6 & 168.2 & $20: 30$ \\
2004 & 137.1 & 108.9 & 133.6 & $20: 00$ \\
2004 & 113.7 & 131.1 & 176.4 & $20: 00$ \\
2005 & 80.3 & 115.7 & 158.3 & $23: 00$ \\
\hline Dec. solstice & $\overline{\mathrm{F} 10.7}$ & $\overline{V_{\text {zonal }}}\left(\mathrm{m} \mathrm{s}^{-1}\right)$ & $V_{\max }\left(\mathrm{m} \mathrm{s}^{-1}\right)$ & $t_{\max }(\mathrm{LT})$ \\
\hline 1999 & 132.2 & 124.9 & 176.8 & $20: 30$ \\
2000 & 178.3 & 134.6 & 150.1 & $21: 00$ \\
2001 & 163.9 & 150.4 & 185.1 & $20: 00$ \\
2003 & 146.3 & 126.1 & 168.9 & $20: 30$ \\
2004 & 127.1 & 126.1 & 154.6 & $21: 00$ \\
2005 & 100.6 & 125.8 & 153.9 & $21: 00$ \\
2006 & 87.2 & 112.6 & 160.6 & $22: 00$ \\
2007 & 86.2 & 96.5 & 125.5 & $21: 30$ \\
\hline & & & &
\end{tabular}

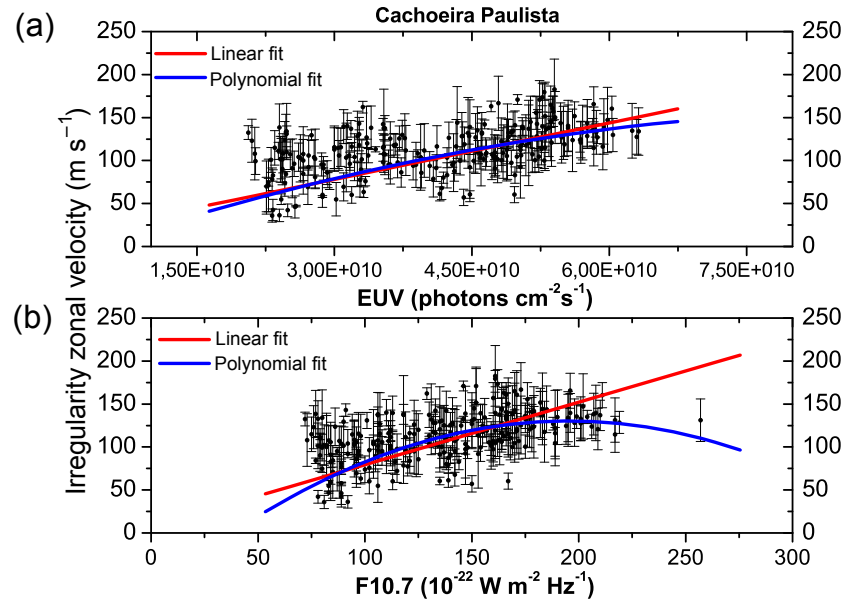

Figure 5. Linear fit (red line) and polynomial fit (blue line) of the daily mean zonal drift velocity of the irregularities estimated at Cachoeira Paulista from 22:00 to 24:00 LT versus daily values of the EUV flux (a) and F10.7 index values (b).

al. (2013), and the authors observed a slower rate of increase in F10.7 in comparison to the increase in the EUV flux for high solar flux values, which might explain the nonlinearity feature depicted here in the plot of $V_{\text {zonal }}$ versus the F10.7 index. The solar flux effects on irregularity zonal velocities have also been studied by Sobral et al. (2009) based on the formulations presented by Haerendel et al. (1992) and Eccles (1998). They discussed the fact that around solar maximum years the magnitude of the thermospheric zonal wind velocities tends to be larger owing to an enhanced solar thermal tide. Therefore, for higher solar flux levels the increase we have observed in the irregularity zonal motion is possi- bly associated with an increase in the Pedersen-conductivityweighted F-region zonal neutral wind.

\subsection{Statistical characterization of amplitude scintillation}

This section presents, for the proposed $\alpha-\mu$ model, the results of the first- and second-order statistical characterization of amplitude scintillation at the equatorial anomaly crest region. We intend with this analysis to provide statistical values that a GNSS user might be susceptible to when dealing with geophysical conditions similar to those found in this study. We have chosen GPS scintillation data available during specific years that represent three different levels of solar activity, i.e., near the solar maximum (year 2000), a moderate or intermediate level during the descending phase of cycle 23 (year 2005), and near the solar minimum (year 2010). The cases for solar maximum cover the period January-February 2000; for the intermediate cycle the cases are within the period of November-December 2005, and for solar minimum the cases selected occurred in the months of February-March and November-December 2010. All measurements of the GPS L1 amplitude scintillation used as input in the model were conducted at Cachoeira Paulista.

It is well known that very intense signal fluctuation associated with scintillation can cause GNSS receivers to stop tracking the signals from the satellites, provoking the socalled loss of lock. It happens when the carrier-to-noise $\left(\mathrm{C} / \mathrm{N}_{0}\right)$ ratio for the receiver to continue tracking a satellite goes below $26-30 \mathrm{dBHz}$ for the $\mathrm{L} 1$ frequency (Kintner et al., 2007; de Paula et al., 2007). Thus, we have chosen cases with no occurrence of loss of receiver lock, which was considered a difficult task and reduced the set of data to be 
analyzed, since loss of lock is a very common process during the occurrence of strong scintillation. Loss of receiver lock during very strong scintillation events tends to occur more frequently when there is a close alignment between the magnetic field lines and the satellite-to-receiver signal paths (DasGupta et al., 2004; Moraes et al., 2017). However, this geometrical factor should not be considered a general rule. In order to increase the number of cases for the statistical characterization, we also included in the analysis the satellites with elevation angles greater than $30^{\circ}$. We then selected data sets in which the $S_{4}$ index values varied from $0.4 \pm 0.025$ to at least $0.9 \pm 0.025$. A total of 21 days met these criteria and were considered in the analysis: 6 days for solar maximum (10, 28, 29 January and 4, 10, 17 February 2000), 8 days for moderate solar activity (23 November and 2, 4, 7, 8, 17, 23, 30 December 2005), and 7 days for solar minimum (17, 21 February, 11, 20 March, 12, 18 November, and 29 December 2010). For these days, Table 2 summarizes the number of cases (in intervals of $60 \mathrm{~s}$ ) that attained the different levels of the $S_{4}$ index.

As previously discussed, the decorrelation time $\tau_{0}$ is an important parameter that provides information about receiver vulnerability. In order to calculate the $\tau_{0}$ it is necessary to compute the autocorrelation coefficients by using Eq. (3). As pointed out by Moraes et al. (2012), a time series of signal fading with similar values of the $S_{4}$ index may present distinct decorrelation time, revealing the importance of the estimation of this parameter due to its implications for GNSS receiver performance. Table 3 presents the average values of decorrelation time $E\left[\tau_{0}\right]$ for the data sets shown in Table 2 . According to the results presented in the table, it is possible to observe that $E\left[\tau_{0}\right]$ tends to decrease with an increasing $S_{4}$ index. Also, the values of $E\left[\tau_{0}\right]$ are in close agreement for almost all cases analyzed during the three different periods of solar activity. The only exception occurred for $S_{4}=0.7$ for the solar minimum period, but the $E\left[\tau_{0}\right]$ is still in agreement with the typical expected values, as presented by Moraes et al. (2012). Analyzing Table 3 it is also possible to observe that the amplitude scintillation fades are decorrelated between a range of 0.50 and $0.90 \mathrm{~s}$. Shorter or longer decorrelation times may be found. As discussed by Kintner et al. (2004), under particular conditions in which the user and the satellites are coupled with the irregularity and moving in the same direction, longer fades with slower temporal variations are expected, which may result in higher values of $\tau_{0}$. The opposite situation is also applicable with a satellite signal crossing the irregularity in the opposite direction of its displacement.

In the next step, the shapes of the $\alpha-\mu$ model distributions for the normalized amplitude envelope are investigated for the different values of the $S_{4}$ index and during different phases of solar activity. Figure 6a shows a case of amplitude scintillation with $S_{4}=0.8$ for solar maximum. Using the $\alpha-\mu$ model with the coefficients estimated by the equality of moments in Eq. (5), Fig. 6b illustrates the successful
Table 2. Total of cases analyzed for different levels of the $S_{4}$ scintillation index during the periods of maximum (Max), moderate (Mod), and minimum (Min) solar activity levels.

\begin{tabular}{lrrrrrr}
\hline$S_{4}( \pm 0.025)$ & 0.4 & 0.5 & 0.6 & 0.7 & 0.8 & 0.9 \\
\hline Max & 136 & 86 & 74 & 45 & 40 & 11 \\
Mod & 40 & 21 & 7 & 5 & 4 & 2 \\
Min & 54 & 27 & 13 & 7 & 3 & 1 \\
\hline
\end{tabular}

Table 3. Average value of decorrelation time $\boldsymbol{E}\left[\tau_{0}\right]$ (in seconds) as a function of the $S_{4}$ scintillation index for the periods of maximum (Max), moderate (Mod), and minimum (Min) solar activity levels.

\begin{tabular}{lrrrrrr}
\hline$S_{4}( \pm 0.025)$ & 0.4 & 0.5 & 0.6 & 0.7 & 0.8 & 0.9 \\
\hline Max & 0.82 & 0.80 & 0.73 & 0.71 & 0.63 & 0.62 \\
Mod & 0.83 & 0.87 & 0.81 & 0.77 & 0.69 & 0.72 \\
Min & 0.80 & 0.79 & 0.70 & 0.50 & 0.46 & 0.40 \\
\hline
\end{tabular}

adjustment of the model to the empirical distribution. This case was obtained for the satellite PRN 2 on 4 February 2000. In particular, it is possible to note that the $\alpha-\mu$ distribution adjusts fairly well with the normalized amplitude scintillation data, mainly in the tail region of the distribution, providing a realistic estimate for the statistics of the received signal. This adaptability is one of the advantages of this model, which is considered to outperform other probability density functions with only one coefficient, such as Nakagami- $m$ or Rice. It is important to mention that the $\alpha-\mu$ model tends to raise the tail as the $\alpha$ parameter increases, taking the lower region of intensity values where the probabilities are higher. Therefore, the increased $\alpha$ coefficient for the same $S_{4}$ value represents a harsher scenario for propagation, with a higher chance of the occurrence of deep fades. More details about the fit capability and approximations for theoretical work can be found in Moraes et al. (2012) and Oliveira et al. (2014).

For a more complete scenario and using the data sets of cases listed in Table 2, Fig. 7 depicts the empirical distribution of amplitude scintillation for the $S_{4}$ index varying from 0.4 up to 0.9 . It is worth pointing out that most of the distributions agree very well for solar maximum (red line), moderate activity (blue line), and solar minimum (green line) periods, in particular for $S_{4}<0.8$. For strong scintillation of the wave field with $S_{4}=0.8$ and $S_{4}=0.9$, the empirical distributions during the different periods of solar activity tend to show some differences, mainly in the tail region. Possible reasons for this may be the distinct spatial variations in the electron density through the medium and the drift velocities of scintillation during different periods of the solar cycle. The regime of strong scintillation of the wave field is known to be the combined result of the effects of multiple scattering and diffraction by the irregularities inside the ionospheric layer (Zernov and Gherm, 2015), which introduces significant changes in the statistical characteristics of propagating 

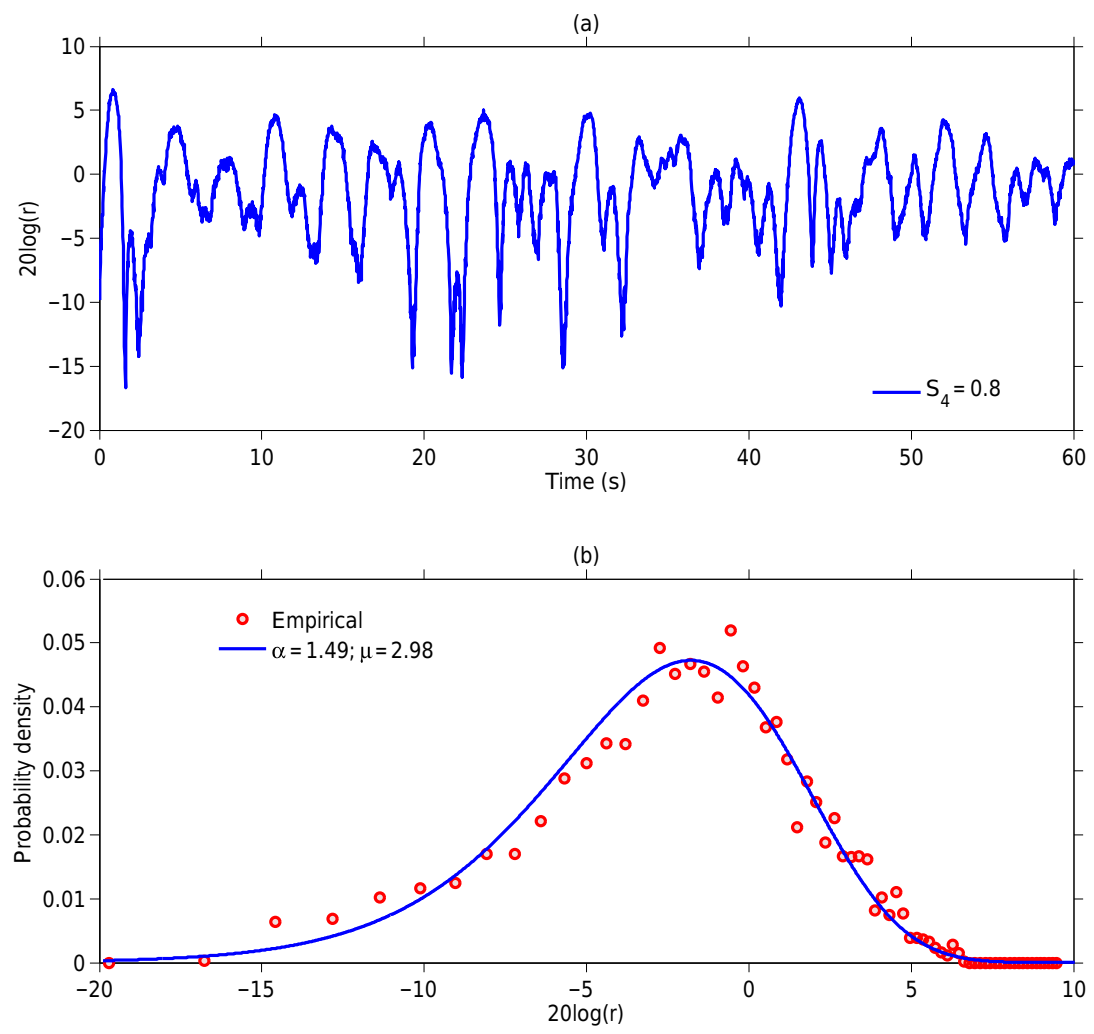

Figure 6. (a) Case of amplitude scintillation with $S_{4}=0.8$ for satellite PRN2 on 4 February 2000. (b) Theoretical $\alpha-\mu$ model based on the moment estimation of Eq. (4) in comparison with the measured occurrences from panel (a).

waves. Therefore, multiple deep fading levels tend to characterize the L1 signal amplitude fluctuations. Additionally, as discussed in Kintner et al. (2004), those variations result in different Fresnel lengths and propagation paths that directly affect the scintillation pattern.

Using the equality of moments in Eq. (5) to estimate the $\alpha-\mu$ pair of values, Table 4 summarizes the average values of the $\alpha$ coefficient as a function of $S_{4}$ for the different periods of solar activity. We note that the $\alpha$ values in most of the cases are less than 2, which supports the use of the $\alpha-\mu$ model since there is an infinite number of $\alpha$ and $\mu$ values that satisfy Eq. (6). It is known that the Nakagami-m distribution can be obtained from the $\alpha-\mu$ model by setting $\alpha=2$. Thus, the present results suggest that the fades have $a$ tail that is less raised than in the Nakagami- $m$ case. Furthermore, the Nakagami- $m$ model may be considered as a conservative approach based on the analysis presented here. It can also be interpreted from Table 4 that for a given scintillation index $S_{4}$, the $\alpha-\mu$ model may describe different patterns of scintillation during different solar activity levels. This is an advantage of the $\alpha-\mu$ model against the popular Nakagami- $m$ distribution, as also addressed by Oliveira et al. (2014).

The second-order statistical evaluation of the ionospheric scintillation amplitude fading events, designated level cross- ing rate (LCR) and average fading duration (AFD), is also presented for the three periods of solar activity levels. As mentioned before, the LCR and AFD parameters are connected to the temporal characteristics of fading events. According to Moraes et al. (2014), these parameters may help to estimate how often the fades will exceed certain thresholds of the amplitude envelope $r$ and how long they are expected to last. Figure 8 shows an example of the theoretical formulation of Eqs. (7) and (8) versus the empirical LCR and AFD values for the cases in which $S_{4}=0.67 \pm 0.025$. The plots in the top, middle, and bottom pairs of panels respectively correspond to periods of solar maximum, moderate, and minimum. The solid line in magenta is the formulation of Eqs. (7) and (8) for $\alpha=1.67$ repeated in the three respective plots for comparison. We used this optimum $\alpha$ value based on the previous results of Moraes et al. (2014), who reported an $\alpha$ range of 1.64-1.69 for the $S_{4}$ index value around 0.67 . By comparing the theoretical formulation of LCR and AFD against scintillation data, the authors concluded that for moderate and weak levels of scintillation $\left(S_{4}<0.7\right)$ the $\alpha-\mu$ model agrees quite well with the values of amplitude envelope $r$. Otherwise, for $S_{4}>0.7$ the model tends to become more conservative, which means that it predicts longer fades and also more crossings for the deeper region of the fades. 
Table 4. Average values of the fading coefficient $\alpha$ as a function of the $S_{4}$ scintillation index for different solar activity levels.

\begin{tabular}{lrrrrrr}
\hline$S_{4}$ & $0.4 \pm 0.025$ & $0.5 \pm 0.025$ & $0.6 \pm 0.025$ & $0.7 \pm 0.025$ & $0.8 \pm 0.025$ & $0.9 \pm 0.025$ \\
\hline Max & 1.76 & 1.22 & 1.08 & 0.73 & 0.78 & 0.67 \\
Mod & 1.99 & 1.89 & 1.07 & 0.52 & 2.50 & 3.6 \\
Min & 1.56 & 1.21 & 1.1 & 0.99 & 0.40 & 0.36 \\
\hline
\end{tabular}
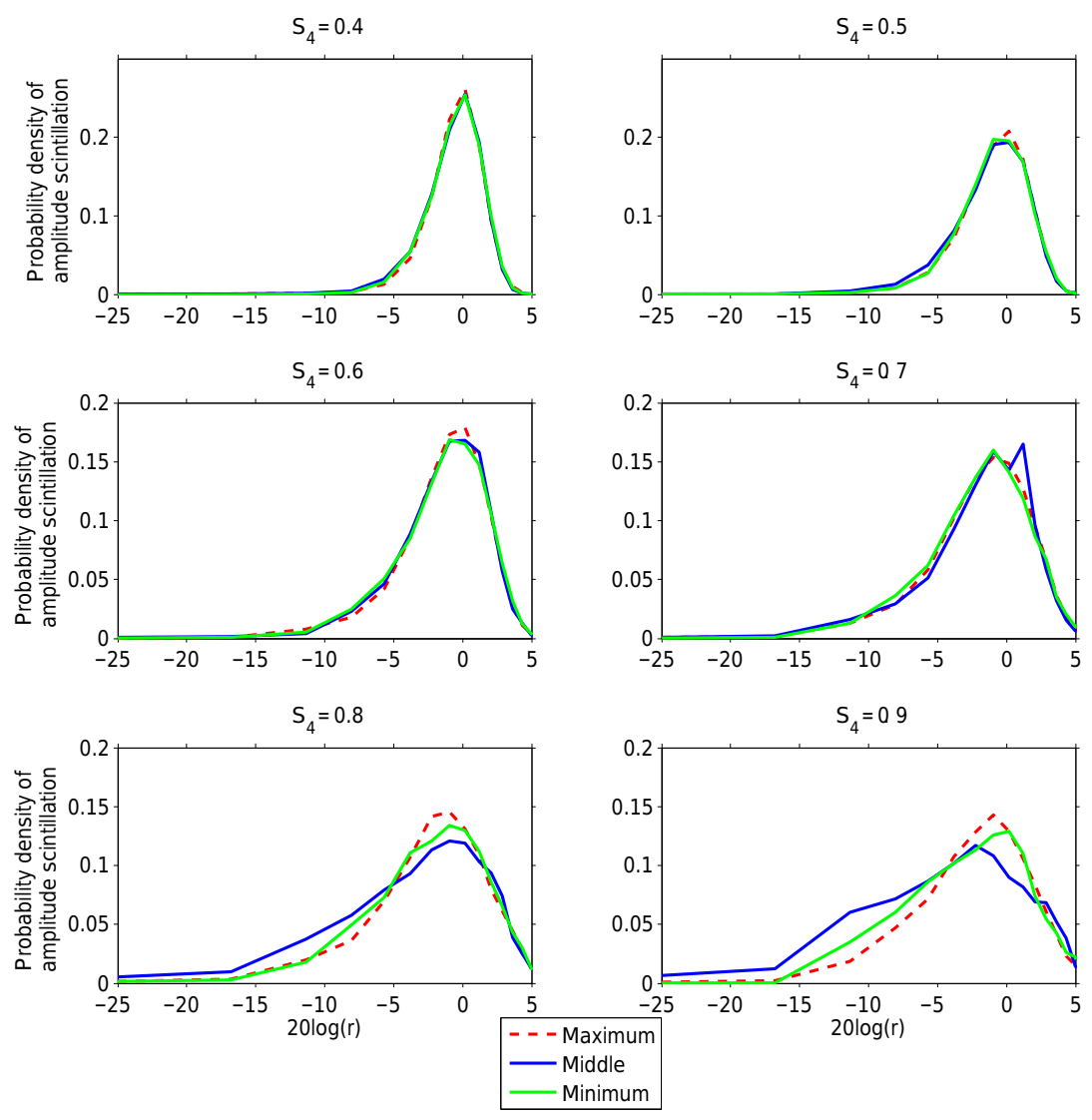

Figure 7. Distribution of measured normalized amplitudes for the $S_{4}$ index from 0.4 to 0.9 for the different periods of solar activity (solar maximum, moderate level, and solar minimum).

In the panels on the left side of Fig. 8, it is possible to note that the LCR for the three solar activity periods has similar behavior. For the AFD plots on the right side it is possible to note again the good fit between the field data and the theoretical formulation. These results clearly suggest that the statistical characteristics of scintillation remain similar throughout the solar cycle, and one cannot assume that the number of fades and their time duration will be different from solar maximum to solar minimum. In other words, the severity of scintillation seems not to be directly linked with solar activity itself, but with the scale size and strength of the irregularities, mainly with the signal propagation path along the irregularity structure. In terms of GPS channel characterization, the typical AFD and LCR values shown in Fig. 8 for the anomaly region might help GNSS receiver developers to estimate out- age rate and duration, evaluate GNSS receiver vulnerabilities under scintillating environments, and design more robust receivers that are less susceptible to the effects of ionospheric scintillation.

\section{Conclusions}

This study investigated the climatology and modeling of ionospheric radio-wave scintillations over Cachoeira Paulista, a Brazilian GNSS station located under the southern crest of the EIA. 

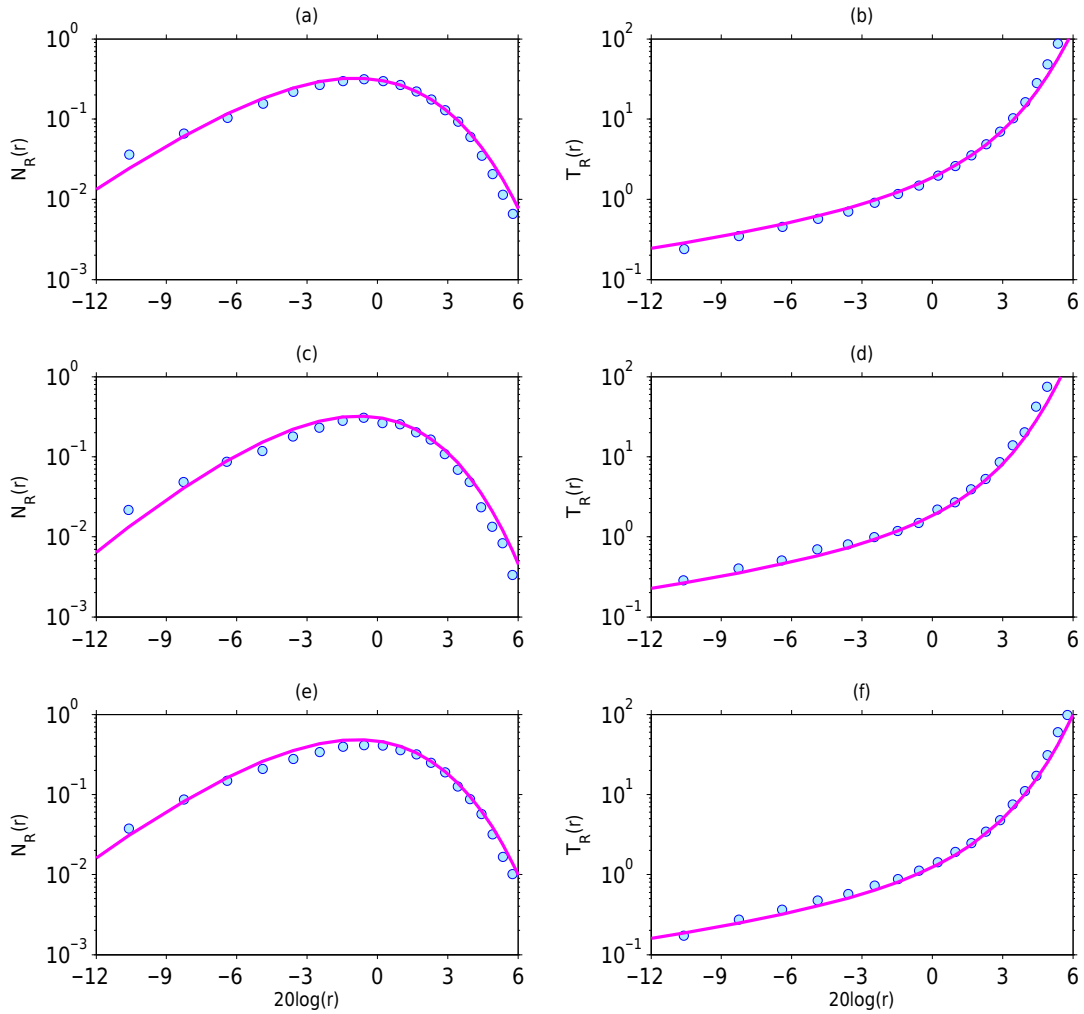

Figure 8. Empirical LCR (crossings per second; panels a, c, e) and AFD (in seconds; panels b, d, f) during the three distinct phases of solar activity level versus the scintillation severity as estimated by the theoretical $\alpha-\mu$ model (Eq. 5) for $S_{4}=0.67$.

The occurrence of scintillations observed from the climatological analysis showed that the Fresnel-scale irregularities causing scintillations at the amplitude of GPS L1 signals are more frequent from September to March, mainly during premidnight hours. The observed seasonal distribution of scintillation occurrence follows the longitudinal characteristics of the occurrence of equatorial plasma bubbles for the eastern coast of South America, with a maximum in the scintillation occurrence around the December solstice months. This is due to the large magnetic declination angle over the region, with a good alignment between the sunset terminator and the magnetic meridians around the summer months.

The mostly marked aspect resulting from the climatological analysis of ionospheric scintillations was their solar activity variations throughout solar cycle 23 until the maximum of the present solar cycle 24 . The largest frequency of occurrence of $\sim 80 \%$ was observed in 2001-2002 around the solar maximum of cycle 23 . After the year 2002, the overall occurrence and strength of scintillations tended to subside with the decrease in solar activity. Following the long declining phase of solar cycle 23 is the deep solar minimum period that occurred from 2007 to 2009 when the lowest occurrence of scintillations was attributed to the suppression of the fountain effect and the anomalous reduction in the background electron density observed at the EIA region. In the first half of solar cycle 24 , considered to be the weakest solar cycle in more than a century, the maximum occurrence of scintillations was $\sim 20 \%$ lower than that observed during the maximum of the previous solar cycle.

The dip latitude of Cachoeira Paulista increased $\sim 3.2^{\circ}$ from 1997 to 2014 and it is possible that, in addition to the solar cycle dependence, the occurrence climatology of scintillations is also being modulated by the drifts in the magnetic dip equator. The crest of the EIA displaced northward of $\mathrm{Ca}$ choeira Paulista from 1997 to 2014, which means that the site is currently located further under the poleward edge of the southern EIA region. Consequently, in the present solar cycle for the plasma bubbles to extend to the site of Cachoeira Paulista, they have to rise to comparatively much higher altitudes above the magnetic equator, thus affecting the local scintillation activity.

The average magnitude of the nocturnal GPS-estimated eastward drift velocities of the irregularities over the lowlatitude station of Cachoeira Paulista was larger during the December solstice months than during the equinoxes. The results revealed the tendency for the irregularity drift velocities to increase with increasing EUV and $10.7 \mathrm{~cm}$ solar fluxes. Depending on the season and solar activity level, the irregularity zonal drifts tended to peak from 20:00 to 23:00 LT. 
In terms of scintillation modeling, the results showed that the shape of the distribution of measured normalized amplitudes and the statistical profile of the scintillating signals do not change significantly through the solar cycle. The values of the parameter $\tau_{0}$, which is a temporal indication of fading characteristics, decreases with the increasing $S_{4}$ index independently of the solar activity. Furthermore, for the same value of the $S_{4}$ index the decorrelation time tends to decrease with the decline in the solar activity. The formulation for the $\alpha-\mu$ distribution was revisited and the estimated pairs of fading coefficients $\alpha-\mu$ also supported the fact that the statistical characteristics of scintillation remain stable during periods of different solar activity levels.

The field data have also been analyzed for second-order statistics, designated level crossing rate (LCR) and average fading duration (AFD), and again the results showed that the $\alpha-\mu$ formulation fits very well for most of the range of the amplitude envelope measured during different levels of solar activity. This result shows that for the same value of the $S_{4}$ index the statistical characteristics of scintillation are similar independently of the solar activity level.

Data availability. The F10.7 data were obtained from Natural Resources Canada (NRC) at http://www.spaceweather.gc.ca/solarflux/ sx-5-en.php. The SOHO and SEM EUV data were taken from University of Southern California (USC) at https://dornsifecms.usc. edu/space-sciences-center/download-sem-data/. The geomagnetic data were analyzed from the World Data Center for Geomagnetism, Kyoto at http://wdc.kugi.kyoto-u.ac.jp/. The GPS scintillation data used in this study may be acquired by contacting the coordinator responsible at INPE (Eurico de Paula, e-mail: eurico.paula@inpe.br).

Author contributions. MTAHM and ERdP designed the experiments and carried them out. MHDS, LFCdR, and MTAHM analyzed the data and plotted the graphs. AOM and BJA developed the fading model and performed the simulations. MTAHM and LA prepared the paper with the contributions of all coauthors.

Competing interests. The authors declare that they have no conflict of interest.

Special issue statement. This article is part of the special issue "Space weather connections to near-Earth space and the atmosphere". It is a result of the $6^{\circ}$ Simpósio Brasileiro de Geofísica Espacial e Aeronomia (SBGEA), Jataí, Brazil, 26-30 September 2016.

Acknowledgements. Marcio T. A. H. Muella wishes to acknowledge support from the Conselho Nacional de Desenvolvimento Científico e Tecnológico (CNPq; grants nos. 304674/2014-1 and 429885/2016-4) and the São Paulo Research Foundation (FAPESP) (process no. 2014/09240-7). Marcelo H. Duarte-Silva is grateful for the support provided by Coordenação de Aperfeiçoamento de Pessoal de Nível Superior (CAPES) under the PROSUP program and Fundação Vale Paraibana de Ensino (FVE). Eurico R. de Paula and Alison O. Moraes acknowledge support from CNPq through grants 310802/2015-6 and 465648/2014-2, respectively.

The topical editor, Mangalathayil Abdu, thanks Andrew Akala, Archana Bhattacharyya, and two anonymous referees for help in evaluating this paper.

\section{References}

Aarons, J.: Global morphology of ionospheric scintillation, Proc. IEEE, 70, 360-378, https://doi.org/10.1109/PROC.1982.12314, 1982.

Abdu, M. A., de Medeiros, R. T., Sobral, J. H. A., and Bittencourt, J. A.: Spread F plasma bubble vertical rise velocities determined from spaced ionosonde observations, J. Geophys. Res., 88, 9197-9204, https://doi.org/10.1029/JA088iA11p09197, 1983.

Abdu, M. A., Batista, I. S., Sobral, J. H. A., de Paula, E. R., and Kantor, I. J.: Equatorial ionospheric plasma bubble irregularity occurrence and zonal velocity under quiet and disturbed conditions from Polarimeter observations, J. Geophys. Res., 90, 99219928, https://doi.org/10.1029/JA090iA10p09921, 1985.

Akala, A. O., Doherty, P. H., Valladares, C. E., Carrano, C. S., and Sheehan, R.: Statistics of GPS scintillations over South America at three levels of solar activity, Radio Sci., 46, RS5018, https://doi.org/10.1029/2011RS004678, 2011.

Akala, A. O., Amaeshi, L. L. N., Somoye, E. O., Idolor, R. O., Okoro, E., Doherty, P. H., Groves, K. M., Carrano, C. S., Bridgwood, C. T., Baki, P., D'ujanga, F. M., and Seemala, G. K.: Climatology of GPS amplitude scintillations over equatorial Africa during the minimum and ascending phases of solar cycle 24, Astrophys. Space Sci., 357, 17, https://doi.org/10.1007/s10509015-2292-9, 2015.

Anderson, D. N. and Mendillo, M.: Ionospheric conditions affecting the evolution of equatorial plasma depletions, Geophys. Res. Lett., 10, 541-544, https://doi.org/10.1029/GL010i007p00541, 1983.

Basu, S., Basu, S., Aarons J., McClure, J. P., and Cousins, M. D.: On the coexistence of kilometer- and meter-scale irregularities in the nighttime equatorial F region, J. Geophys. Res., 83, 4219-4226, https://doi.org/10.1029/JA083iA09p04219, 1978.

Basu, S., Kudeki, E., Basu, Su., Valladares, C. E., Weber, E. J., Zengingonul, H. P., Bhattacharyya, S., Sheehan, R., Meriwether, J. W., Biondi, M. A., Kuenzler, H., and Espinoza, J.: Scintillations, plasma drifts, and neutral winds in the equatorial ionosphere after sunset, J. Geophys. Res., 101, 26795-26809, https://doi.org/10.1029/96JA00760, 1996.

Beach, T. L. and Kintner, P. M.: Development and use of a GPS ionospheric scintillation monitor, IEEE T. Geosci. Remote Sens., 39, 918-928, https://doi.org/10.1109/36.921409, 2001.

Bhattacharyya, A., Basu, S., Groves, K. M., Valladares, C. E., and Sheehan, R.: Dynamics of equatorial F region irregularities from spaced receiver scintillation observations, Geophys. Res. Lett., 28, 119-122, https://doi.org/10.1029/2000GL012288, 2001.

Bhattacharyya, A., Kakad, B., Sripathi, S., Jeeva, K., and Nair, K. U.: Development of intermediate scale structure near the peak of the F region within an equatorial plasma bubble, J. Geophys. 
Res., 119, 3066-3076, https://doi.org/10.1002/2013JA019619, 2014.

Bhattacharyya, A., Kakad, B., Gurram, P., Sripathi, S., and Sunda, S.: Development of intermediate-scale structure at different altitudes within an equatorial plasma bubble: implications for Lband scintillations, J. Geophys. Res.-Space, 121, 1015-1030, https://doi.org/10.1002/2016JA023478, 2017.

Carrano, C. S. and Groves, K. M.: Temporal decorrelation of GPS satellite signals due to multiple scattering from ionospheric irregularities, in: Proceedings of the ION GNSS-10, Portland, OR, Institute of Navigation, 361-374, 2010.

Carrano, C. S., Valladares, C. E., and Groves, K. M.: Latitudinal and local time variation of ionospheric turbulence parameters during the conjugate point equatorial experiment in Brazil, Int. J. Geophys., 2012, 103963, https://doi.org/10.1155/2012/103963, 2012.

Cesaroni, C., Spogli, L., Alfonsi, L., Franceschi, G. D., Ciraolo, L., Monico, J. F. G., Scotto, C., Romano, V., Aquino, M., and Bougard, B.: L-band scintillations and calibrated total electron content gradients over Brazil during the last solar maximum, J. Space Weather Space Clim., 5, A36, https://doi.org/10.1051/swsc/2015038, 2015.

Chatterjee, S. and Chakraborty, S. K.: Variability of ionospheric scintillation near the equatorial anomaly crest of the Indian zone, Ann. Geophys., 31, 697-711, https://doi.org/10.5194/angeo-31697-2013, 2013.

DasGupta, A., Ray, S., Paul, A., Banerjee, P., and Bose, A.: Errors in position-fixing by GPS in an environment of strong equatorial scintillations in the Indian zone, Radio Sci., 39, RS1S30, https://doi.org/10.1029/2002RS002822, 2004.

de Paula, E. R., Kherani, E. A., Abdu, M. A., Batista, I. S., Sobral, J. H. A., Kantor, I. J., Takahashi, H., Rezende, L. F. C., Muella, M. T. A. H., Rodrigues, F. S., Kintner, P. M., Ledvina, B. M., Mitchell, C., and Groves, K. M.: Characteristics of the ionospheric irregularities over Brazilian longitudinal sector, Indian J. Radio Space, 36, 268-277, 2007.

de Paula, E. R., Muella, M. T. A. H., Sobral, J. H. A., Abdu, M. A., Batista, I. S., Beach, T. L., and Groves, K. M.: Magnetic conjugate point observations of kilometer and hundred-meter scale irregularities and zonal drifts, J. Geophys. Res., 115, A08307, https://doi.org/10.1029/2010JA015383, 2010.

de Paula, E. R., Jonah, O. F., Moraes, A. O., Kherani, E. A., Fejer, B. G., Abdu, M. A., Muella, M. T. A. H., Batista, I. S., Dutra, S. L. G., and Paes, R. R.: Low-latitude scintillation weakening during sudden stratospheric warming events, J. Geophys. Res.Space, 102, 2212-2221, https://doi.org/10.1002/2014JA020731, 2015.

Eccles, J. V.: A simple model of low-latitude electric fields, J. Geophys. Res., 103, 26699-26708, https://doi.org/10.1029/98JA02657, 1998.

Engavale, B., Jeeva, K., Nair, K. U., and Bhattacharyya, A.: Solar flux dependence of coherence scales in scintillation patterns produced by ESF irregularities, Ann. Geophys., 23, 3261-3266, https://doi.org/10.5194/angeo-23-3261-2005, 2005.

Fejer, B. G., Souza, J. R., Santos, A. S., and Pereira, A. E. C.: Climatology of $F$ region zonal plasma drifts over Jicamarca, J. Geophys. Res., 110, A12310, https://doi.org/10.1029/2005JA011324, 2005.
Fremouw, E. J., Livingston, R. C., and Miller, D. A.: On the statistics of scintillating signals, J. Atmos. Terr. Phys., 42, 717-731, https://doi.org/10.1016/0021-9169(80)90055-0, 1980.

Hady, A. A.: Deep solar minimum and global climate changes, J. Adv. Res., 4, 209-214, https://doi.org/10.1016/j.jare.2012.11.001, 2013.

Haerendel, G. E., Eccles, J. V., and Çakir, S.: Theory of modeling the equatorial evening ionosphere and the origin of the shear in the horizontal plasma flow, J. Geophys. Res., 97, 1209-1223, https://doi.org/10.1029/91JA02226, 1992.

Hao, Y. Q., Shi, H., Xiao, Z., and Zhang, D. H.: Weak ionization of the global ionosphere in solar cycle 24, Ann. Geophys., 32, 809-816, https://doi.org/10.5194/angeo-32-809-2014, 2014.

Hegarty, C., El-Arini, M. B., Kim, T., and Ericson, S.: Scintillation modeling for GPS-Wide Area Augmentation system receiver, Radio Sci., 36, 1221-1231, https://doi.org/10.1029/1999RS002425, 2001.

Humphreys, T. E., Psiaki, M. L., Hinks, J. C., O’Hanlon, B., and Kintner, P. M.: Simulating ionosphere-induced scintillation for testing GPS receiver phase tracking loops, IEEE J. Sel. Top. Sig., 3, 707-715, https://doi.org/10.1109/JSTSP.2009.2024130, 2009.

Humphreys, T. E., Psiaki, M. L., and Kintner, P. M.: Modeling the effects of ionospheric scintillation on GPS carrier phase tracking, IEEE T. Aero. Elec. Sys., 46, 1624-1637, https://doi.org/10.1109/TAES.2010.5595583, 2010.

Kil, H., Kintner, P. M., de Paula, E. R., and Kantor, I. J.: Global positioning system measurements of the ionospheric zonal apparent velocity at Cachoeira Paulista in Brazil, J. Geophys. Res., 105, 5317-5327, https://doi.org/10.1029/1999JA000244, 2000.

Kil, H., Kintner, P. M., de Paula, E. R., and Kantor, I. J.: Latitudinal variations of scintillation activity and zonal plasma drifts in South America, Radio Sci., 37, 1006, https://doi.org/10.1029/2001RS002468, 2002.

Kintner, P. M., Ledvina, B. M., de Paula, E. R., and Kantor, I. J.: Size, shape, orientation, speed, and duration of GPS equatorial anomaly scintillations, Radio Sci., 39, RS2012, https://doi.org/10.1029/2003RS002878, 2004.

Kintner, P. M., Ledvina, B. M., and de Paula, E. R.: GPS and ionospheric scintillations, Space Weather, 5, S09003, https://doi.org/10.1029/2006SW000260, 2007.

Ledvina, B. M., Kintner, P. M., and de Paula, E. R.: Understanding spaced-receiver zonal velocity estimation, J. Geophys. Res., 109, A10306, https://doi.org/10.1029/2004JA010489, 2004.

Liu, L. B., Chen, Y., Le, H., Kurkin, V. I., Polekh, N. M., and Lee, C.-C.: The ionosphere under extremely prolonged low solar activity, J. Geophys. Res., 116, A04320, https://doi.org/10.1029/2010JA016296, 2011.

Liu, K., Li, G., Ning, B., Hu, L., Li, H.: Statistical characteristics of low-latitude ionospheric scintillation over China, Adv. Space Res., 55, 1356-1365, https://doi.org/10.1016/j.asr.2014.12.001, 2015.

Martinis, C., Eccles, J. V., Baumgardner, J., Manzano, J., and Mendillo, M.: Latitude dependence of zonal plasma drifts obtained from dual site airglow observations, J. Geophys. Res., 108, 1129, https://doi.org/10.1029/2002JA009462, 2003.

Moraes, A. O., Rodrigues, F. S., Perrela, W. J., and de Paula, E. R.: Analysis of the characteristics of low-latitude GPS amplitude scintillation measured during solar maximum conditions and im- 
plications for receiver performance, Surv. Geophys., 33, 11071131, https://doi.org/10.1007/s10712-011-9161-z, 2011.

Moraes, A. O., de Paula, E. R., Perrella, W. J., and Rodrigues, F. S.: On the distribution of GPS signal amplitudes during the low-latitude ionospheric scintillation, GPS Solutions, 17, 499, https://doi.org/10.1007/s10291-012-0295-3, 2012.

Moraes, A. O., de Paula, E. R., Muella, M. T. A. H., and Perrela, W. J.: On the second order statistics for GPS ionospheric scintillation modeling, Radio Sci., 49, 94-105, https://doi.org/10.1002/2013RS005270, 2014.

Moraes, A. O., Costa, E., Abdu, M. A., Rodrigues, F. S., de Paula, E. R., Oliveira, K., and Perrela, W. J.: The variability of low-latitude ionospheric amplitude and phase scintillation detected by a triple-frequency GPS receiver, Radio Sci., 52, https://doi.org/10.1002/2016RS006165, 2017.

Muella, M. T. A. H., de Paula, E. R., and Monteiro, A. A.: Ionospheric scintillation and dynamics of Fresnel-scale irregularities in the inner region of the equatorial ionization anomaly, Surv. Geophys., 34, 233-251, https://doi.org/10.1007/s10712012-9212-0, 2013.

Muella, M. T. A. H., de Paula, E. R., and Jonah, O. F.: GPS L1-frequency observations of equatorial scintillations and irregularity zonal velocities, Surv. Geophys., 35, 335-357, https://doi.org/10.1007/s10712-013-9252-0, 2014.

Oliveira, K., Moraes, A. O., Costa, E., Muella, M. T. A. H., de Paula, E. R., and Perrela, W.: Validation of the $\alpha-$ $\mu$ model of the power spectral density of GPS ionospheric amplitude scintillation, Int. J. Antennas Propag., 573615, https://doi.org/10.1155/2014/573615, 2014.

Otsuka, Y., Shiokawa, K., and Ogawa, T.: Equatorial ionospheric scintillations and zonal irregularity drifts observed with closelyspaced GPS receivers in Indonesia, J. Meteorol. Soc. Jpn., 84, 343-351, 2006.

Priyadarshi, S.: A review of ionospheric scintillation models, Surv. Geophys., 36, 295-324, https://doi.org/10.1007/s10712015-9319-1, 2015.

Rangarajan, G. K. and Barreto, L. M.: Secular change in the location of the magnetic dip equator in the twentieth century, Geofis. Intern., 39, 323-336, 2000.

Santos, A. M., Abdu, M. A., Sobral, J. H. A., Mascarenhas, M., and Nogueira, P. A. B.: Equatorial evening prereversal vertical drift dependence on solar EUV flux and F10.7 index during quiet and disturbed periods over Brazil, J. Geophys. Res., 118, 4662-4671, https://doi.org/10.1002/jgra.50438, 2013.

Santos, A. M., Abdu, M. A., Souza, J. R., Sobral, J. H. A., and Batista, I. S.: Disturbance zonal and vertical plasma drifts in the Peruvian sector during solar minimum phases, J. Geophys. Res., 121, 2503-2521, https://doi.org/10.1002/2015JA022146, 2016.

Sheehan, R. E. and Valladares, C. E.: Equatorial ionospheric zonal drift model and vertical drift statistics from UHF scintillation measurements in South America, Ann. Geophys., 22, 31773193, https://doi.org/10.5194/angeo-22-3177-2004, 2004.

Sobral, J. H. A., Abdu, M. A., Takahashi, H., Taylor, M. J., de Paula, E. R., Zamlutti, C. J., Aquino, M. G., and Borba, G. L.: Ionospheric plasma bubble climatology over Brazil based on 22 years (1977-1998) of $630 \mathrm{~nm}$ airglow observations, J. Atmos. Sol.-Terr. Phy., 64, 1517-1524, https://doi.org/10.1016/S13646826(02)00089-5, 2002.
Sobral, J. H. A., Abdu, M. A., Pedersen, T. R., Castilho, V. M., Arruda, D. C. S., Muella, M. T. A. H., Batista, I. S., Mascarenhas, M., de Paula, E. R., Kintner, P. M., Kherani, E. A., Medeiros, A. F., Buriti, R. A., Takahashi, H., Schuch, N. J., Denardini, C. M., Zamlutti, C. J., Pimenta, A. A., Souza, J. R., and Bertoni, F. C. P.: Ionospheric zonal velocities at conjugate points over Brazil during the COPEX campaign: experimental observations and theoretical validations, J. Geophys. Res., 114, A04309, https://doi.org/10.1029/2008JA013896, 2009.

Solanki, S. K., Krivova, N. A., Schüssler, M., and Fligge, M.: Search for a relationship between solar cycle amplitude and length, Astron. Astrophys., 396, 1029-1035, https://doi.org/10.1051/0004-6361:20021436, 2002.

Solomon, S. C., Woods, T. N., Didkovsky, L. V., Emmert, J. T., and Qian, L.: Anomalously low solar extreme ultraviolet irradiance and thermospheric density during solar minimum, Geophys. Res. Lett., 37, L16103, https://doi.org/10.1029/2010GL044468, 2010.

Spogli, L., Alfonsi, L., Romano, V., Franceschi, G. D., Monico, J. F. G., Shimabukuro, M. H., Bourgard, B., and Aquino, M.: Assessing the GNSS scintillation climate over Brazil under increasing solar activity, J. Atmos. Sol.-Terr. Phy., 105-106, 199-206, https://doi.org/10.1016/j.jastp.2013.10.003, 2013.

Srinivasu, V. K. D., Brahmanandam, P. S., Uma, G., Prasad, D. S. V. V. D., Rao, P. V. S. R., and Mukherjee, S.: Long-term morphological and power spectral studies of VHF amplitude scintillations recorded over Waltair $\left(17.7^{\circ} \mathrm{N}\right.$, 83.3 E), India, Terr. Atmos. Ocean. Sci., 28, 385-394, https://doi.org/10.3319/TAO.2016.11.08.01, 2016.

Valladares, C. E., Meriwether, J. W., Sheehan, R., and Biondi, M. A.: Correlative study of neutral winds and scintillation drifts measured near the magnetic equator, J. Geophys. Res., 107, SIA7-1-SIA7-15, https://doi.org/10.1029/2001JA000042, 2002.

Yacoub, M. D.: The $\alpha-\mu$ distribution - a physical fading model for the stacy distribution, IEEE Trans. Veh. Technol., 56, 24-27, https://doi.org/10.1109/TVT.2006.883753, 2007.

Yeh, K. C. and Liu, C. H.: Radio-wave scintillations in the ionosphere, Proc. IEEE, 70, 324-360, https://doi.org/10.1109/PROC.1982.12313, 1982.

Zernov, N. N. and Gherm, V. E.: Strong scintillation of GNSS signals in the inhomogeneous ionosphere: 1. Theoretical background, Radio Sci., 50, 168-176, https://doi.org/10.1002/2014RS005603, 2015.

Zhang, H., Liu, Y., Wu, J., Xu, T., and Sheng, D.: Observations and modeling of UHF-band scintillation occurrence probability over the low-latitude region of China during the maximum activity of solar cycle 24, Ann. Geophys., 33, 93-100, https://doi.org/10.5194/angeo-33-93-2015, 2015. 